\title{
INCLUSIVE HUMAN RESOURCE DEVELOPMENT - THE FRUIT OF INCLUSIVE GROWTH IN INDIA
}

\author{
Jyoti Kumari Sharma *1凶 \\ ${ }^{* 1}$ Assistant Professor, Department of Economics, Balurghat College, Ph.D Scholar, Department of \\ Economics, Raiganj University, India
}

DOI: https://doi.org/10.29121/granthaalayah.v9.i1.2021.3142

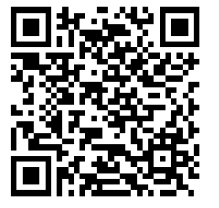

Article Type: Research Article

Article Citation: Jyoti Kumari Sharma. (2021). INCLUSIVE HUMAN RESOURCE DEVELOPMENT - THE FRUIT OF INCLUSIVE GROWTH IN INDIA. International Journal of Research -GRANTHAALAYAH, 9(1), 302-329.

https://doi.org/10.29121/granthaa layah.v9.i1.2021.3142

Received Date: 25 December 2020

Accepted Date: 31 January 2021

Keywords:

National Integration

Resource Development

Inclusive Growth, Skill Development

Paradoxica

Mental Capability

Human Resource Development

Productive Capacity

Physical Capability

\section{ABSTRACT}

Under the a national consciousness, the national integration refers to process which is to bring all the different race, religions, cultures and linguistic groups together into one single nation. It aims at removing sociocultural, economic inequality and strengthening unity by giving human dignity to all citizens without any discrimination. We know that India represents a paradoxical dynamic economy, among high economic processes followed by a rise in indifference, poverty, and regional imbalances. Under this, it was found that the development of abilities and skills of human beings under human resource development enhances the use of physical capitals' successfully, positively, and progressively. It is done by educating, providing better health facilities, and developing skills of the country's citizens, helps them to add to productivity, increasing the national wealth of the country.

Accordingly, when Human Resource Development is more inclusive, respect and understanding grow. Further, inclusive Human Resource Development strategy increases the productivity of the country, with the development of productive capacity, physical capability, and mental capability of its human resources, which leads to all-round economic development and growth of the country. In this way, through my studymade in this paper, I look forward to describe and explain the process of reducing all kinds of socio-economic exclusion from India by implementing the inclusive growth strategy that helps to reduce poverty with the help of the income (wages) earned from the jobs of each citizen, guaranteeing food security, education, health, employment, etc. facilities for all. Thus, inclusive Human Resource Development strategy can reduce and remove inequality from India, accompanied by social welfare with stability.

\section{1) INTRODUCTION}

Human resources refer to the country's manpower, which is taken as capital assets, which yield economic benefits in the country's economic life and working structure. Under the economic studies and surveys made, it is often found that the physical capital formation, along with human capital formation that is human resource development is also important for all economic development and growth of the concerned country's economy. It refers to the development of abilities and skills of human beings under human resource development that enhances the use of physical capitals' successfully, positively, and progressively. Human resource development is taken as a

(C) 2021 The Author(s). This is an open access article distributed under the terms of the Creative Commons Attribution License, which permits unrestricted use, distribution, and reproduction in any medium, provided the original author and source are credited. 
process of human capital development needed for the country's development, increasing its productive capacity. It is so because of the following reasons:

The cost incurred in educating and improving the mental capability of human beings-citizens of the country helps them to increase the productivity of the concerned country. It is with the positive and successful use of their knowledge gained through education.

The cost incurred in providing better health facilities to its citizens adds to the healthy human force with good physical capability. It gives and works to increase the productivity of a country under a hygienic, safe, and healthy life.

The cost incurred on the development of skills of the country's citizens helps them to add to productivity, increasing the national wealth of the country. Thus, it moves towards the enhancement of their productive capacity heading towards the successful use of all resources both positively and progressively of the concerned country.

So, with an increase in productivity of the country, with the development of productive capacity, physical capability, and mental capability of its human resources, leads to all-round economic development and growth of the country.

On the basis of this, the concept of INCLUSIVE HUMAN RESOURCE DEVELOPMENT act as the fruit of inclusive growth that arises from activities that help increase of country's human capital productivity. It is possible only by providing education, health, and skill development facilities, both inclusively and equally to all citizens heading towards human resource development of the concerned country.

\section{2) INCLUSIVE HUMAN RESOURCE DEVELOPMENT}

Inclusive Human Resource Development of a country refers to all its managerial activities done to develop and enhance the productive capacity, mental capability, and physical capability of its citizens provided through education, health, and on-job-training facilities. In this way, the country by properly using its manpower for the best utilization of its physical capital and natural resources increases the productivity of different sectors of the economy, adding to its national wealth progressively. It leads to an increase in the country's economic growth positively with prosperity heading towards all-round economic development of the country with sustainability.

Economists named Theodore $\mathbf{W}$. Schultzlisted the following five such activities for the successful implementation of inclusive human resource development in any country. These are as follows:

1) Formally organized education at elementary, secondary, and higher levels.

2) Health facilities including its services, broadly conceived to include expenditures that affect all health structure. Thus, it includes life expectancy, strength with an increase in stamina and vigour along with the vitality of life.

3) On- the-job training, including old-style apprenticeships organized by firms.

4) Study programmes for adults that are organized firms, including extension programmes notably in agriculture.

5) Migration of individuals, families, or both, to adjust to changing job opportunities.

Further, economists named Frederick Harbison and Charles A. Myers divided the indicators of human resource development into two basic parts, that is:-

1) Those which measures the country's stock of human capital. and

2) Those which measure the gross and net addition to this stock, which is the rate of human capital formation over a specified period of time.

The above are on national levels and for international comparison related to the development of human capital resources of the country, they gave the following two important indicators:

1) Levels of educational attainment of the human capital of the country. and

2) The number of persons, in relation to population or labor-force, who are in high-level occupations like scientists, engineers, doctors, teachers, etc. 
In this way, the improvement in productive capacity, physical capability, and mental capability developmental facilities is a necessity in the field of inclusive human resource development in any country. It helps to give its citizens a knowledge-full life through education, healthy and hygienic life under health facilities, and skill-full life with onjob training programmes. Helping its citizens to produce more and adding progressively to national wealth, which is considered equivalent to investments done in various physical capital formation activities for economic growth and development.

\section{3) ESSENTIAL COMPONENTS OF INCLUSIVE HUMAN RESOURCE DEVELOPMENT}

Human resource development is very important to increase and enhance the economic growth of any country, as human resources of the concerned country are those assets that yield a stream of economic benefits over their working life. Here opportunities related to education (literacy), health, physical, environmental facilities, etc, must be equally present for all people (citizens) in the concerned country, irrespective of sex, caste, creed, political freedom, etc. heading towards inclusive human resource development.

On the basis of inclusive human resource development the following components are very important, and thus are necessary and essential for its successful and positive implementation in any country. These components help to widen people's choices, with improvement in the levels of their well-being with respect to their productive capacity, mental capability, and physically healthy life. These four essential components are as follows:

\section{Equity}

For inclusive growth heading towards the economic development of the country, equality plays a very important part. It enlarges citizen's choices with equitable access to all opportunities of the concerned country. Thus, equality with respect to opportunities, heading towards restructuring of concerned country's manpower on inclusive terms includes the following processes:

1) Equitable distribution of productive assets.

2) Equitable distribution of income under the progressive fiscal policy, aiming at transfer from rich to poor.

3) Restructuring the country's credit system, answering overhauling credit requirements of poor on equitable terms of all.

4) Equalization related to the democratic system, with respect to political opportunities reforms related to voting rights, campaign finance, etc.

5) To provide equality concerning economic and political opportunities by undertaking steps to remove social and legal barriers, which limits the access of women, ethnic minorities, and other socioeconomic minorities, etc

\section{Sustainability}

It refers to human resources development in such a manner that the next generation gets the right to enjoy the same well-being related to the human development paradigm. Thus, sustainability acts as an important component of human resource development. Under this context, the sustainability of human resource development acts as a matter of distributional equity, to share developmental opportunities between the present and future generations. In this way, it ensures equity in access to all the development opportunities related to human capital resources. So, accordingly, every worthwhile life opportunity for human resources development must be sustained, removing all kinds of human deprivation to bring in inclusive human resource development.

\section{Productivity}

Productivity refers to essential efforts to increase productive capacity, mental capability, and physically healthy life of the manpower-human capital present in the country. It adds to enhancement (increase) the productivity of the country, both positivity and progressively under the process of inclusive human resource development.

So, accordingly, the development of the productivity of human resources enables investment in manpowerhuman capital of the country at the macroeconomic level to achieve their maximum potential for the economic development of the country. For example, East Asian economics like Japan and Korea shows that by tremendous investment in their human resources concerning their education, health, etc. Hence, the models of economic development should primarily focus on the human resource development under accelerated economic growth. In 
Jyoti Kumari Sharma

this way, we can achieve inclusive human resource development heading towards an increase in their productivity following equality on sustainable terms and conditions.

\section{Empowerment}

Empowerment means that people legally have full freedom to make the right choices as per their will. As, even if there is equality, sustainability, and productivity, but cannot work as per their will, it is not complete human resource development. Thus, the fourth component takes in empowerment as a component of human resource development under inclusion. Accordingly, to implement it under legal terms and conditions of the country, the procedures are as follows:

1) To ensure investment in education and health, giving full advantage, to legally take the right choice under education market opportunities'.

2) To ensure access to credit and other productive assets on legal terms and conditions to all human resources, helping them to make the right choice related to their movements of life and its activities.

3) To empower both men and women with equality, that is no gender discrimination in any field, helping them to compete with each other concerning all the development opportunities present in and around the world.

In this way, we see how equity, sustainability, productivity, and empowerment acts as the four pillars necessary to hold the walls of human resource development to build the house of inclusive growth with sustainability for the citizens of the concerned country. Further, it brings forward the importance of real-governance as a doorstep for every citizen, including all members of civil society and non- governmental organizations, to give their full participation with freedom of choice in making and implementing decisions of all-round socio-economic development.

\section{4) POLICIES AND PROGRAMMES OF INCLUSIVE HUMAN RESOURCE DEVELOPMENT IN INDIA}

Under this, the Government of India aimed to give a secured and better livelihood heading towards Inclusive Human Resource Development in India through their education, health, and employment situation, taking the help of infrastructural facilities heading towards balanced regional development to Indian citizens. For this, the Government of India implemented the following policies, programmes, and schemes, which are as follows:

1) In 1950, the Government of India introduced a vocational training scheme named CRAFTSMAN TRAINING SCHEME (CTS) to reduce unemployment among skilled workers. This scheme provided a steady flow of systematic training related to skill development to all educated youths through vast networks of IITs. In this way, it ensured to raise the quality and quantity of industrial production, by cultivating and motoring technical and industrial attitude in the young generation youth present in India.

2) In 1967, the programme named SHRAMIK VIDYAPEETH was introduced to provide skill-development training to non-literates, school drop-outs, neo-literates, etc, present in India. It aimed to provide a livelihood to the beneficiaries in terms of self and wage employment, national and state-related portal related to the promotion of employment, along with job meals. Later, in April 2000, this scheme was revised and renamed as JAN SHIKSHAN SANSTHAN. It followed the principles of life-enrichment of economically backward and disadvantaged citizens of India, living in both rural and urban areas. It aimed at providing skill training as per their education and identifying their skills, along with digital literacy, helping them with better employment opportunities.

3) In 1970, the Government of India launched QUALITY IMPROVEMENT PROGRAMME (QIP) to imbibe a culture of research with better educational teaching capabilities of the faculty members employed and working in degree-level colleges, institutions, etc. This programme is monitored by the "All India Council for Technical Education (AICTE)", and it only sponsors teachers eligible for both MASTERS AND DOCTORAL DEGREE programmes.

4) In 1972, the Government of India launched NEHRU YUVA KENDRA SANGATHAN (NYKS) to integrate the power of rural-educated youths with respect to principles of self-help and voluntarism followed by community participation. In this way, it helped and helps these youths to take part in the nation-building process of India, with the development of their skill and personality. 
5) In 1982, the Government of India launched PANDIT DEEN DAYAL UPADHYAY NATIONAL WELFARE FUND FOR SPORTSPERSONS (PDUNWFS). It is to provide financial assistance to outstanding sportspersons that are both men and women, living in vulnerable circumstances and thus needed various help like money for their medical treatment.

6) On 5th May 1988, the then Prime minister of India, Shri. Rajiv Gandhi implemented NATIONAL LITERACY MISSION, with the aim to impart functional literacy to non-literates of India, under the age group of 15-35 years. And in this way to make them self-reliant with respect to reading, writing, and numerical calculations. Under this, the main objective was to eradicate illiteracy from India and make all Indian citizens aware of the development issues of the country.

7) On 25th December 2000, the then Prime minister of India, Shri. Atal Bihari Vajpayee launched the ANTYODAYA ANNA YOJANA, with the motive to provide subsidized food to all poor-families of India. In this way, it aimed to increase their health capacity and productive capability under a healthy life of subsidized food.

8) On 5th August 2008, a credit-linked subsidy programme named PRIME MINISTER'S EMPLOYMENT GENERATION PROGRAMME (PMEGP) was launched, by merging the two developmental schemes, which are:

- PRIME MINISTER ROJGAR YOJANA and

- RURAL EMPLOYMENT GENERATION PROGRAMME.

Under this, the aim is to facilitate continuous and sustainable employment opportunities for both rural and urban unemployed people. It is by the establishment of micro-enterprises in both rural and urban areas of India.

9) In 2009-10, the then Prime minister of India, Shri. Manmohan Singh launched a rural development programme named PRADHAN MANTRI ADARSH GRAM YOJANA. It was to allocate the financial funds to villages having a high rate that is over 50 percent of people belonging to scheduled caste. This scheme was formed, by merging both state and central programmes of India, which are Bharat Niram, Pradhan Mantri Gram Sadak Yojana, Sarva Siksha Abhiyan, MNREGA, and Integrated Child Development Services.

10) On 23rd September 2013, a scheme named SEEKKHO AUR KAMAO was launched, in India. It is related to the learning come earning process. Further, it followed the process to conserve the traditional skills and improve the employability of minorities by updating and establishing linkages in the labour-market for them. Thus, it ensured their placement of minorities under the employment sector of India.

11) In 2013-14, a scheme named PADHO PARESH came into existence in India to provide 'interest subsidy' for monitoring the Indian students studying at Master's, M. Phil, and Ph.D. level in international countries. Interest subsidy was provided, in terms of financial assistance with regular invigilation of their standards, concerning their studies and performance at the literacy level, as per their degree.

12) On 4th March 2014 an innovative faculty development programme named NALANDA SCHEME was launched, to improve the quality of various academic programmes. It was through its aim of helping the faculty members to learn and implement new ways in their teaching processes to achieve excellence and growth.

13) On 26th August 2014, the PADHE BHARAT BADHE BHARAT scheme was launched to improve and increase the foundational quality of the educational learning process in India. Its main aim is to provide appropriate learning in terms of reading, writing, and numerical understanding and its solving, followed by language comprehension to students of India, particularly by class I and class II.

14) On 25th September 2014, a youth employment scheme named DEEN DAYAL UPADHYAY GRAMEEN YOJANA (DDU-GKY) was launched for skilling the rural youth with occupational aspirations of placement initiative. In this way, it aimed to enhance the skills of the rural youth of India for wage-employmen.

15) On 16th November 2014 various labour reforms were introduced by the present Prime Minister- Mr. Narendra Modi, under SHRAMEV JAYATE YOJANA. Its main aim was to provide a conducive environment towards industrial development with labour reforms allowing international businesses in India. the reforms were as follows: 
- Labour issues should be seen from the view of the "SHRAMIK", which means labour, not through the objective of an industrialist.

- To make the Indian businesses full of opportunities through easy government facilities with e-governance heading towards the effective and transparent government.

- It enabled the portability of Indian businesses through a universal account number of EPF subscribers.

- It enabled reforms to encourage the self-attestation of citizens. This was to enhance ease of compliance, increasing productivity, and employability in the country.

- Various steps were also taken to increase the potential of the IIT's institutions and their skills. So that they can provide a skilled Indian labour force at both national and international levels.

16) On 11th November 2014, under the All India Council for Technical Education-AICTE, the SAKSHAM SCHEME was launched for encouraging and supporting the able youths of India with education. Its main objective was to encourage them to study further and pursue technical education, helping them with opportunities to get gainful employment successfully in the future.

17) Again on 11th November 2014, the scheme named UNNAT BHARAT ABHIYAN (UBA) was launched to build an enhancing architecture in India by leveraging technological knowledge institutions under the process of transformational change in rural development. Under this, the main objective was to evolve appropriate technologies focused on water management, renewable energy, organic farming, frugal technology, etc. It is to upgrade the capabilities of rural citizens, in terms of their livelihood through improvement in the rural infrastructure and an increase in their employment opportunities under this programme.

18) In November 2014, a project named UDAAN was launched in India to address the problem of the low enrolment of girls in various engineering institutions. Under, this the main objective was to take efforts to enrich and develop the teaching and learning process at the school level, with respect to subjects under science and mathematics. In this way, the government of India aimed to reduce/remove gender inequality, followed by raising the standard of the Indian education system under school education, heading towards engineering entrance examinations.

19) In the year 2014, the KNOWLEDGE, INVOLVEMENT RESEARCH ADVANCEMENT THROUGH NURTURING (KIRAN) scheme was launched for women scientists and researchers. Its main aim is to provide them with scholarships, particularly to them who are self-employed and to the one's who had faced any break in their research career due to their household reasons.

20) On 25th March 2015, a scheme on "Pro-Active Governance and Timely Implementation" named PRAGATI was launched to provide unique interactive and integrating government platforms to address the common man's grievances. Under this government of India implemented various policies and programmes to monitor and simultaneously review India's efficiency and responsiveness towards the development process.

21) On 8th April 2015, the present Prime Minister- Mr. Narendra Modi, launched a scheme named PM MUDRA YOJANA to create an inclusive and sustainable value-based entrepreneurial culture in India. Under this, loan up to 10 lakh was to be provided to the non-corporate, non-farm small, and micro-enterprises, helping them to move towards economic success through financial security and stability.

22) On 14th May 2015, the 'UPGRADING THE SKILLS AND TRAINING IN TRADITIONAL ARTS/ CRAFTS FOR DEVELOPMENT' (USTTAD) scheme was launched to build and upgrade the capacity of Indian traditional artisans by preserving the traditional arts and crafts heritage of India. For this Indian government aimed and started to establish both national and international market linkages and thus ensured to upgrade the dignity of traditional artisans related to Indian labour with better employment opportunities.

23) On 1st July 2015, the scheme named PRIME MINISTERKRISHI SINCHAYEE YOJANA (PMKSY) was launched, with the motive "HAR KET KO PANI." Under this, the main aim was to reduce water wastage by improving the efficiency of on-farm water use in India through investments in irrigation and other watersaving technologies.

24) On 15th July 2015, the NATIONAL SKILL DEVELOPMENT MISSION was launched, with the vision of "skilled India." The objective of this programme was not only to consolidate but also coordinate efforts on skill development with speed and standard. For this purpose, skill development elements related to 
Inclusive Human Resource Development - The Fruit of Inclusive Growth in India

institutional training and its infrastructure development, convergence, trainers, overseas employment, sustainable livelihood, and leveraging public infrastructure were taken into consideration.

25) On 16th July 2015, a skill development initiative scheme named PRADHAN MANTRI KAUSHAL VIKAS YOJANA (PMKVY) was launched, with the aim to upgrade the standard of skill development process implemented in India. Accordingly, it aims to increase the working efficiency of existing daily-wage workers by providing them with quality training, reward, and monetary awards. Under this, training and assessment fees were completely paid by the government. Further, Rs. 8000/- per person was kept, as an average award. Thus, under this Government of India aimed to give a secure and better livelihood to Indian citizens.

26) On 17th September 2015, the PRADHAN MANTRI KHANIJ KSHETRA KALYAN YOJANA was launched to provide welfare and ensure long term sustainable livelihood to the people affected by and living in mining areas. Under this, government function is to minimize the adverse impacts concerning the environment, health, and socio-economic issues related to people living in mining districts.

27) In 2015, under NITI-AYOG, SELF EMPLOYMENT AND TALENT UTILIZATION (SETU) SCHEME was launched to fully utilize the inner-potentials of all new start-ups, small businesses, and self-employed, particularly technology-driven areas of works. Here, the government provided help and support financially in time and at any place.

28) On 5th April 2016, the STAND-UP INDIA scheme was launched by Prime Minister NARENDRA MODI to support entrepreneurship among women and SC-ST communities.

29) On 19th August 2016, the NATIONAL APPRENTICESHIP PROMOTION SCHEME (NAPS) was launched, to provide and promote apprenticeship training, which consists of basic-training, on-the-job training, and practical training in the workplace. It also aimed to incentivize employers and made provision for sharing expenditure incurred in the process of providing training and provided STIPEND to those who wish to engage in apprentices.

30) On 9th July 2017, the STUDY WEBS OF ACTIVE LEARNING FOR YOUNG ASPIRING MINDS (SWAYAM) scheme was launched in India. It aim to enable the professors and other faculty members of centrally funded institutions to offer online courses to all citizens of India through institutions like IIT's, IIM's, Central University of Haryana, etc.

31) In June 2017, the GREEN SKILL DEVELOPMENT PROGRAMME (GSDP) was launched to provide Biodiversity conversation skill courses. This programme covered branches like pollution monitoring, sewage treatment, forest and wildlife management, water budgeting, etc. Under this, the Indian government also enabled the Indian youths with gainful and self-employment under these bio-geographic sectors.

32) On 26th April 2018, the ATAL INNOVATION MISSION (AIM) was set up by NITI-AAYOG to create and promote innovation under the eco-system of entrepreneurship. Under this, the promotion of entrepreneurship is designed, through the promotion of self-employment and talent utilization by providing a knowledge platform for innovative ideas about entrepreneurship.

33)On 27th February 2019, the SCHEME FOR HIGHER EDUCATION YOUTH IN APPRENTICESHIP AND SKILLS (SHREYAS) was launched to provide apprenticeship opportunities for fresh graduates, basically from non-technical courses. It is through education and skill training platforms, based on industry-specific apprenticeship and helps these degree students to obtain gainful employment.

34) On 12th September 2019, Prime Minister NARENDRA SINGH MODI launched a social security scheme named NATIONAL PENSION SCHEME FOR TRADERS AND SELF-EMPLOYED PERSON to provide old-age protection in terms of voluntary and contributory pension of minimum Rs. 3000/- per month, to small-scale traders and retailers like shop-owners, workshop-owners, etc. Here, the pension is subscribed, after attaining the age of 60 yrs. Further, if the pension-subscriber dies, the spouse of the concerned beneficiary is entitled to receive a family pension of the amount equal to 50 percent of the pension, which was received by the dying subscribe.

Under the implementation of these above-mentioned policies, programmes, and schemes of inclusive human development, the Government of India is trying to help the Indian citizens-human resources with economic liberalization followed by empowerment along with political democracy. Thus, it should always be under socioeconomic control following rules and regulations of the country. Further, helping all the citizens of the country to take right and legal decisions related to the development perspectives of their concerned life progress. 


\section{5) EVOLUTION OF HUMAN DEVELOPMENT INDEX}

The Human Development Index (HDI) is a statistical tool used to measure the overall achievement of a country's human resources, based on the health of its citizens, the attainment of their educational level and their standard of living, depicting the productivity and prosperity of the concerned country, concerning these social and economic dimensions of economic development.

The Human Development Index (HDI) was launched by United Nations Development Program (UNDP) in 1990 to measure the development of human resources/capital present in the country in terms of their education, health, and productivity. It was prepared, under the stewardship, which is the supervision of Mahbub.UL.Haq, taking the help of Gustav Ranis of Yale University and Lord Meghnad Desai of London School of Economics. Under this, HDI is taken as the arithmetic mean of three-dimension indices, which are education index, the health index, and income index. The dimension index is calculated by using the following formula, which is:

\section{Dimension index =}

\section{Actual value - minimum value}

Maximum value- minimum value

As per the UNDP, 1990 method of calculating HDI, the maximum and minimum value of all dimensions index is as follows in table 9.1.

Table 1: UNDP, 1990 maximum and minimum value of all dimensions index

\begin{tabular}{|c|c|c|c|}
\hline Dimension & Measures & Maximum Value & Minimum Value \\
\hline Health index & LIFE EXPECTANCY AT BIRTH & $85 \mathrm{yrs}$ & $25 \mathrm{yrs}$ \\
\hline & ADULT LITERACY RATE & 100 & 0 \\
\cline { 2 - 4 } Education index & GROSS ENROLLMENT RATIO & 100 & 0 \\
\hline Income index & GDP PER CAPITA (PPP US\$) & 40,000 & 100 \\
\hline
\end{tabular}

Following the formula of DIMENSION INDEX and accordingly using the dimensions of each index mentioned above, the HDI measured the education index, health index, and income index in the following manner:

1) HEALTH index- This measures the health facilities present in the country, with respect to LIFE EXPECTANCY AT BIRTH, depicting the long and healthy life of its citizens.

HEALTH index = LIFE EXPECTANCY AT BIRTH index

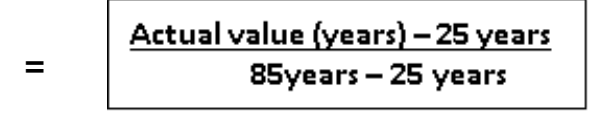

2) EDUCATION index- It measures the quality of educational facilities of the country, in terms of adult literacy rate (with two-third weight) and gross enrolment ratio (with one-third weight). The adult literacy rate was measured with respect to the knowledge gained by its citizens. And at the same, it also measures the gross enrolment ratio with respect to the total number of citizens enrolled for study in primary, secondary, and higher education sectors.

\section{EDUCATION index =}

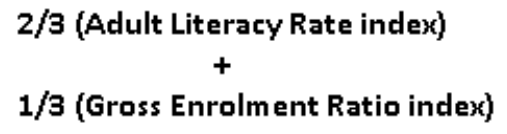

Where; Adult literacy rate index=

Actual value -0 $100-0$ and

Gross enrolment ratio index $=$

Actual value - 0

$100-0$ 
3) INCOME index- It measures the standard of living of the citizens, with respect to GDP per capita income of the country. It indirectly combines the employment of the citizens of the country, which adds to its GDP, increasing the national income of the country.

\section{INCOME index= GDP PER CAPITA index}

$=\frac{\log (\text { Actual value })-\log (100)}{\log (40,000)-\log (100)}$

So, accordingly, from 1990, HDI was taken as the arithmetic mean of these entire three-dimension indices till 2010. On the basis of all the above-mentioned indices, HDI was calculated as follows:

\section{HDI (human development index) =}

HEALTH index + EDUCATION index+ INCOME index

3

In 2010, many criticisms were raised related to the HDI calculation process of 1990. It was in terms of its construction leading to its composition. With respect to this, the policy of inclusive growth HRD, 2010 quoted that, "Many concerns are valid, but the objective is not to build an unusable indicator of well being. It should be to redirect the attention towards human-centered development. Further, it should always promote debate over how we advance the progress of societies."

So, till 2010, HDI was measured in the form of aggregate measures of progress related to health, education, and income. During the year, 2010 the UNDP modified these indicators used to measure the progress of education and income but kept the health indicator the same. At the same time, they also modified the manner in which these indicators were aggregated for measuring HDI. That is the arithmetic mean method used for calculating HDI since 1990 was replaced in 2010 by the geometric mean calculation method, to give equal weight to all three dimension indices, which are as follows:

1) EDUCATION index: Earlier, it was measured in terms of two indicators, which are the adult literacy rate and gross enrolment ratio. In 2010, it was modified by replacing these indicators by mean year of schooling and expected years of schooling respectively. Both of these indicators were given equal weight in calculating the education index. An expected year of schooling is measured on the basis of enrolment by age at all education levels and the official age of the population at all education levels. Means year of schooling is calculated as the average number of years of education received by people aged 25 and above at all education levels in their complete lifetime.

2) INCOME index: Under this, in 2010 the indicator GDP per capita was replaced by GNI per capita for measuring the standard of living of a country's citizens as per its national income. The basic reason for this was that it was found that in this globalized world, there is a very large difference between the income of the country's residents and its domestic production. As some citizens can earn from abroad.

3) HEALTH index: It was kept or remained the same as before in terms of life expectancy at birth.

From 2010, HDI was taken as the geometric mean of these entire three-dimension indices, giving equal weight to all these indices.

As per the new method of calculating the HDI, the UNDP report 2010 with the maximum and minimum value of all dimension indices is shown in table- 9.2:

Table 2: UNDP 2010, maximum and minimum value of all dimensions indices

\begin{tabular}{|c|c|c|c|}
\hline Dimension & Indicators & Maximum Value & Minimum Value \\
\hline $\begin{array}{c}\text { HEALTH } \\
\text { index }\end{array}$ & LIFE EXPECTANCY AT BIRTH (years) & $85 \mathrm{yrs}$ & $20 \mathrm{yrs}$ \\
\hline \multirow{2}{*}{$\begin{array}{c}\text { EDUCATION } \\
\text { index }\end{array}$} & MEAN YEARS OF SCHOOLING (years) & 15 & 0 \\
\cline { 2 - 4 } & EXPECTED YEARS OF SCHOOLING (years) & 18 & 0 \\
\hline
\end{tabular}


Jyoti Kumari Sharma

\begin{tabular}{|c|c|c|c|}
\hline $\begin{array}{c}\text { INCOME } \\
\text { index }\end{array}$ & GNI PER CAPITA (2011 PPP US\$) & 75,000 & 100 \\
\hline
\end{tabular}

Source: https://ourworldindata.org/human-development-index

Thus, under these/above mentioned maximum and minimum values of dimension indices, from the year 2010 HDI is calculated in following manner:

1) HEALTH index = LIFE EXPECTANCY AT BIRTH index =
Actual value (years) -20 years

85 years -20 years

(EXPECTED YEARS OF SCHOOLING index + MEAN YEARS OF SCHOOLING index)/2

EDUCATION index =

Where; EXPECTED YEARS OF SCHOOLING index =

Actual value -0

18-0 and

MEAN YEARS OF SCHOOLING index =

$$
\frac{\text { Actual value }-0}{15-0}
$$

INCOME index = GNI per capita(2011 PPP US\$) index

$$
=\quad \frac{\log (\text { Actual value })-\log (100)}{\log (75,000)-\log (100)}
$$

On the basis of these indices, HDI was calculated as follows:

HDI (human development index) as per UNDP, 2010 is calculated under following method:

$$
\text { HDI }=(\text { HEALTH index. EDUCATION index. INCOME index })^{1 / 3}
$$

Hence, from 2010, HDI was taken as the geometric mean of these entire three dimension indices, giving equal weight to all these indices. Under this following limits were kept to determine the degree of HDI, which are as follows and shown in table 9.3:

Table 3: Degrees and values of HDI

\begin{tabular}{|c|c|}
\hline DERGREE OF HDI & Limits-values of HDI \\
\hline Very high HDI & $0.800-1.000$ \\
\hline High HDI & $0.700-0.799$ \\
\hline Medium HDI & $0.555-0.699$ \\
\hline Low HDI & $0.350-0.554$ \\
\hline
\end{tabular}

So, accordingly, from the year 1990, HDI is taken as the best measure to calculate and get human development reports of a country. It a very appropriate way that helps to understand the real economic position of the society concerning the level of education, health, employment, etc. of the concerned country's human capital/resources.

\section{6) STATISTICAL STATUS OF HUMAN RESOURCE DEVELOPMENT IN INDIA, ALONG WITH ITS MEASUREMENT IN TERMS OF HDI ACCOMPANIED BY HDI INTERNATIONAL COMPARISON}

Human Resource Development is defined on the basis of a formally organized system to improve the physical ability, mental capacity, and productive capability of the citizens of the concerned country. 
Thus, accordingly, the HRD is calculated with the help of the Human Development Index (HDI). These are often variable and susceptible to direct measurement.

\subsection{HUMAN RESOURCE DEVELOPMENT IN INDIA}

HRD measurement is framed, in terms of education level, health facilities, including its services to line a hygienic life and employment status along with its on-the-job training facilities. On the basis, the HRD is measured in terms of the following indicators, which are as follows:

1) Education level in terms of total literacy rate in India.

2) Health facilities in terms of health services present in India.

3) Employment status in terms of percentage shares of different types of employment (UPSS) in India.

These are as follows:

Table 4: TOTAL LITERACY RATE OF INDIA (in percent)

\begin{tabular}{|c|c|c|c|c|}
\hline Census Year & Males & Females & Male-Female Literacy Gap & Total Person \\
\hline 1951 & 27.16 & 8.86 & 18.30 & 18.33 \\
\hline 1961 & 40.40 & 15.35 & 25.05 & 28.30 \\
\hline 1971 & 45.96 & 21.97 & 23.98 & 34.45 \\
\hline 1981 & 56.38 & 29.76 & 26.62 & 43.57 \\
\hline 1991 & 64.13 & 39.29 & 24.84 & 52.21 \\
\hline 2001 & 75.26 & 53.67 & 21.59 & 64.84 \\
\hline 2011 & 82.14 & 65.46 & 16.68 & 74.04 \\
\hline
\end{tabular}

Source: Ministry of human resource development (2014).

National University of Education Planning and Administration: Education for All towards quality with equity, 2014.

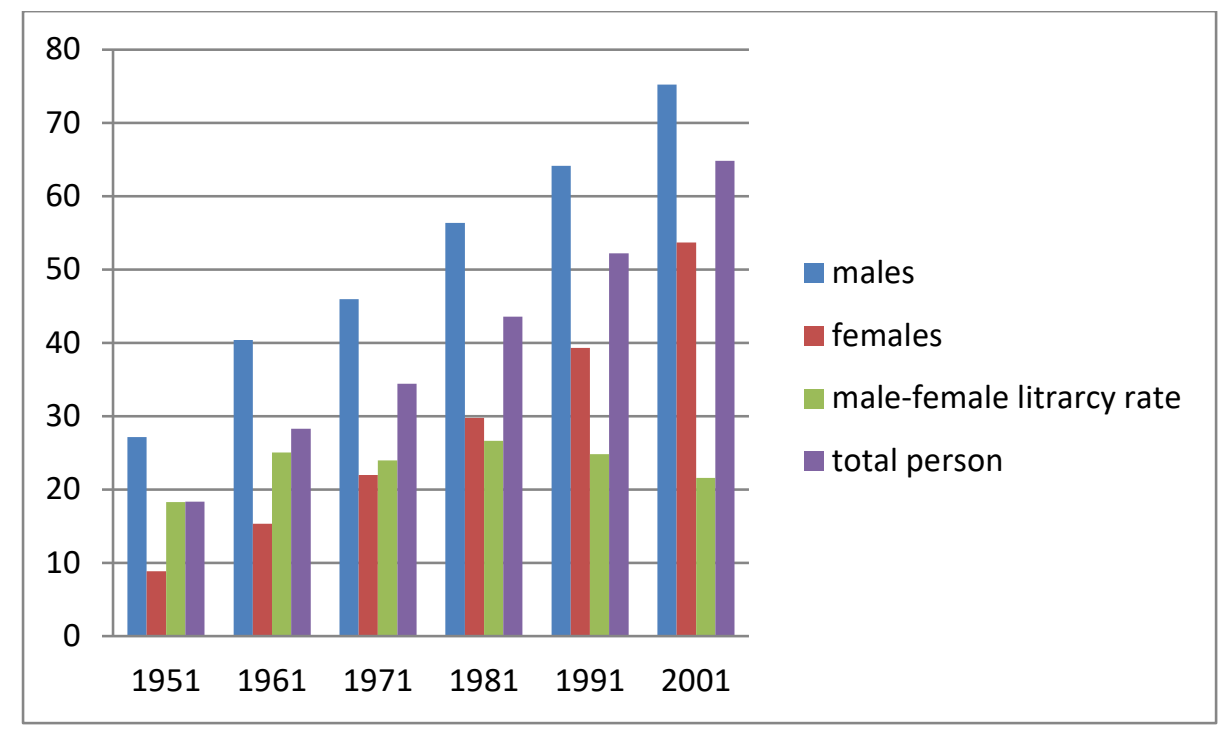

Figure 1: LITERACY RATE OF India (in percent)

Literacy Rate refers to the total percentage of people who can read and write at least in one language. These percentages of people having knowledge and understanding are considered literate.

Accordingly, we see from the above table and figure that after independence, the increase in the literacy rate during the period of 1991-2001 has been highest, which is 52.21 percent to 64.84 percent and then to 74.04 percent in 2011. For the first time, the country witnessed a faster female growth in female literacy, which is from 39.29 percent to 53.67 percent. Then we see that our female literacy rate increased to 65.46 percent. Thus, the gender literacy gap reduced from 24.84 percent in 1991 to 21.59 percent in 2001 and 16.68 percent in 2011. Accordingly, 
we see a very good improvement in literacy rate as per the increasing percentage of literates in India, making and providing the education facilities inclusive in nature.

Table 5: Expansion of health services in India, (1951 to 2015)

\begin{tabular}{|c|c|c|}
\hline Types of health services & $1950-51$ & $2014-15$ \\
\hline Medical colleges & 28 & 398 \\
\hline Dental colleges & N.A & 305 \\
\hline Number of government hospitals & 2,690 & 20,300 \\
\hline Number of dispensaries (AYUSH) & 6,510 & 26,100 \\
\hline Number of health centres & 725 & 1.83 lakh \\
\hline Number of government hospitals beds & 1.17 lakh & 6.76 lakh \\
\hline Number of doctors (allopathic doctors \& dental surgeons) & 61,800 & 10.93 lakh \\
\hline Number of nurses & 18,000 & 25.6 lakh \\
\hline Number of registered doctors per 1,00,000 people & 17 & 76 \\
\hline
\end{tabular}

Source: Ministry of health \& family welfare, central bureau of health intelligence, national health profile, 2015.

From the above table, analysis of inclusive health care facility as per the expansion of health services in India (1951 to 2015) of India can be done bringing forward its positive impact on India's population-citizens.

It is seen that in 1950-51, the number of Medical colleges was only 28, which increased to 398 in 2014-15. Similarly, the number of dental colleges increased to 305 in 2014-15. The number of dispensaries (AYUSH) also increased from 2,690 in 1950-51 to 20,300 in 2014-15.

Related to this, the number of health centers, the number of government hospitals beds, the number of doctors (allopathic doctors and dental surgeons), the number of nurses, and the number of registered doctors (per 1,00,000 people) increased from 725, 1.17 lakh, 61,800, 18,000 and 17 in 1950-51 to 1.83 lakh, 7.76 lakh, 10.93 lakh, 25.6 lakh and 76 lakh in 2014-15 respectively.

In this way, the statistical analysis of inclusive health-care in India shows how progressively and positively health care facilities have developed in India. It is seen from this analysis that it is by following and bringing forward an inclusive growth strategy to achieve sustainable socio-economic development in India, with respect to health facilities for all its citizens and others residing in India. Thus, it is clear from the above table that over the years, the number of health-care services established and people receiving these services under inclusive health-care is growing in India.

Table 6: Status of employment (UPSS), 1983 to 2011-12

\begin{tabular}{|c|c|c|c|c|c|c|}
\hline SHARE (\%) IN TOTAL EMPLOYMENT OF: & 1983 & $1993-94$ & $1999-2000$ & $2004-05$ & $20009-10$ & $2011-12$ \\
\hline REUGLAR WAGE WORKERS & 13.5 & 13.2 & 14.0 & 14.3 & 15.6 & 17.9 \\
\hline FORMAL & - & - & 5.4 & 5.6 & 6.4 & 6.8 \\
\hline INFORMAL & - & - & 8.6 & 8.6 & 9.2 & 11.0 \\
\hline CASUAL WAGE EMPLOYMENT & 29.0 & 32.0 & 33.2 & 28.9 & 33.5 & 29.9 \\
\hline SELF-EMPLOYMENT & 57.5 & 54.7 & 52.8 & 56.9 & 51.0 & 52.2 \\
\hline CASUAL AND SELF EMPLOYMENT & 86.5 & 86.7 & 86.0 & 85.8 & 84.5 & 82.1 \\
\hline ORGANIZED SECTOR & - & - & 9.3 & 11.1 & 14.0 & 16.4 \\
\hline UNORGANIZED SECTOR & - & - & 90.7 & 88.7 & 86.0 & 83.6 \\
\hline
\end{tabular}

Source:-computed from unit level data of various NSSO rounds.

-Institute for human development (2014),

-India labour and employment report 2014. New Delhi: Academic foundation 
Inclusive Human Resource Development - The Fruit of Inclusive Growth in India

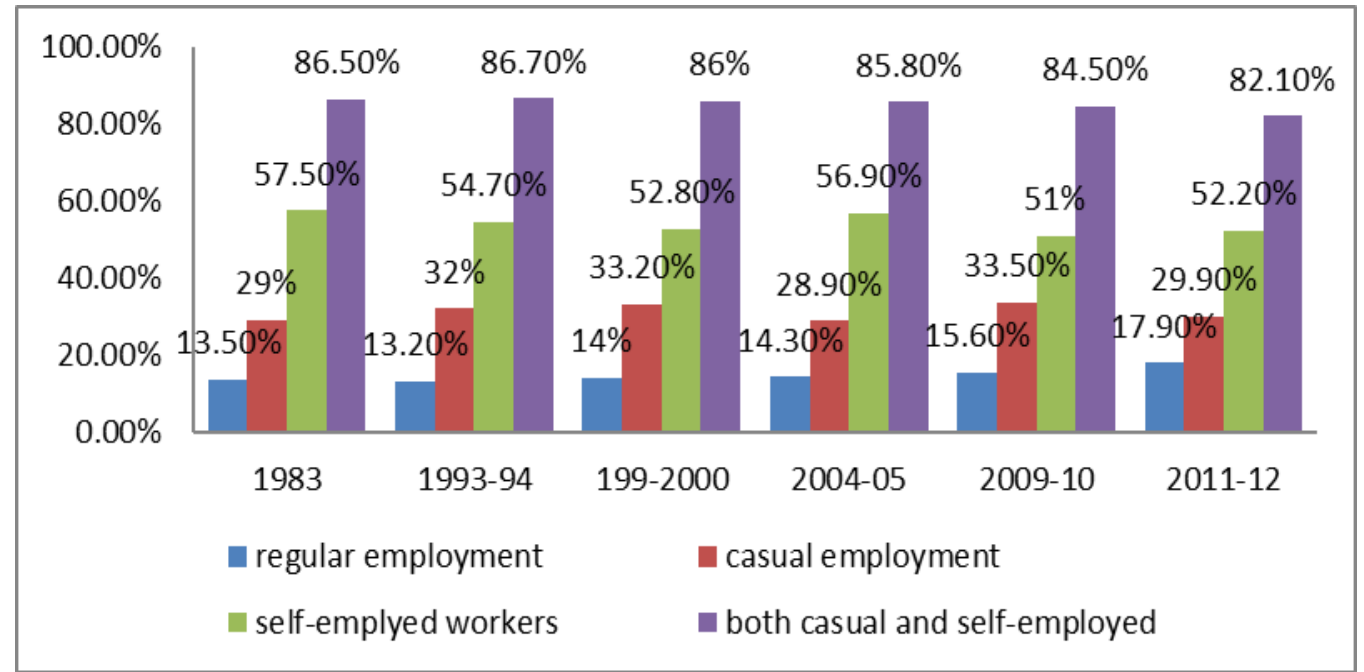

Figure 2 a): Status of employment (UPSS) related to share (\%) in total employment, with respect to regular employment, casual employment and self employed workers and casual-self employed, from 1983 to 2011-12

It is noticed from the above figure that the percentage of employment, related to the regular wage, casual wage, and self-employment has been increased over the years. Among these three types of workers, the self-employed are greater than both the regular-waged and casual-waged workers. If we consider this status of employment we see that, in 1983, the regular-waged workers were 13.5 percent, which increased to 14 percent during 1999-2000 and again to 17.9 percent during 2011-12. Whereas, when we check the status of casual-waged workers, it is seen that in the year 1983, it was 29 percent, which increased to 33.2 percent during 1999-2000, but it decreased to 29.9 percent during 2011-12. Following this trend, we see that self-employment has always followed a decreasing trend, which is that in 1983, it was 57.5 percent, and then declined to 52.8 percent during 1999-2000. Again, during 201112 , it decreased to 52.2 percent.

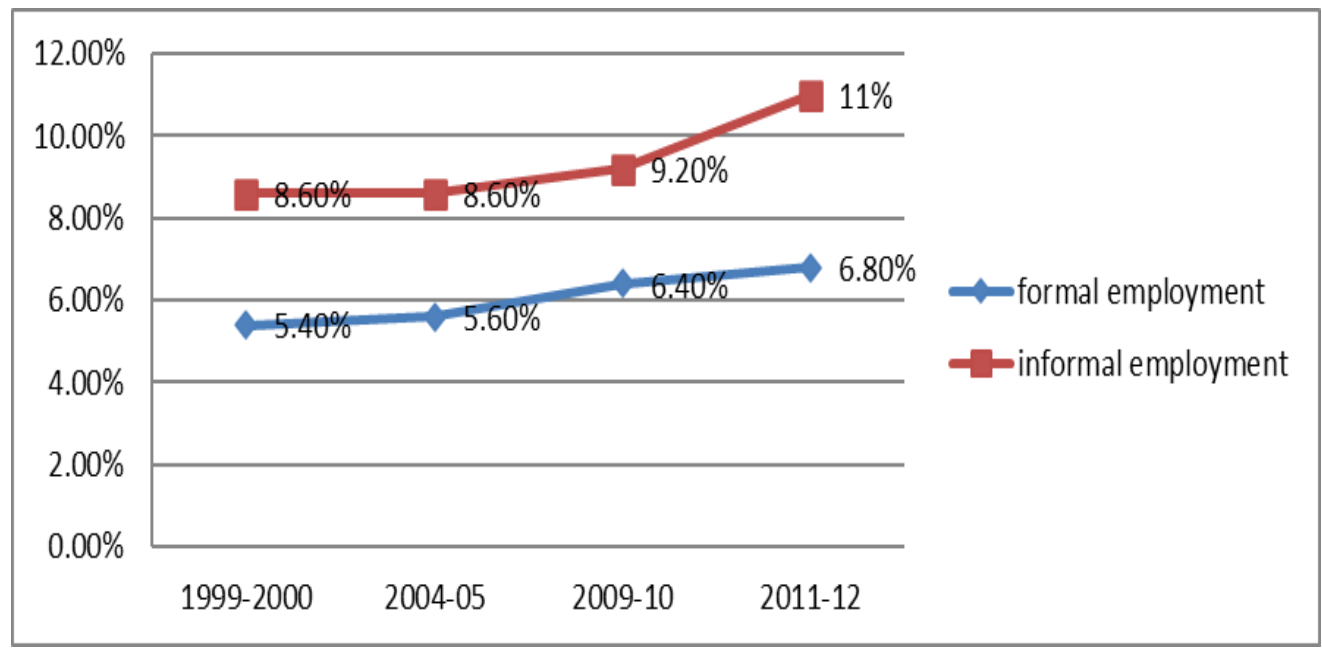

Figure 2 b): Status of employment (UPSS) related to share (\%) in total employment, with respect to formal and informal employment, from 1983 to 2011-12

It is seen from the above figure though the percentage share of the formal and informal sectors has been increasing, over the years, the percentage of workers employed in the informal sector have always been more than that of the formal sector. During 1999-2000, the percentage share of workers employed in the formal sector was 5.4 percent, which increased to 5.6 percent during 2004-05, then to 6.4 percent during 2009-10 and finally to 6.8 percent during 2011-12. Whereas in the informal sector percentage share of workers was 8.6 percent during both 19992000 and 2004-05, then it increased to 9.2 percent during 2009-10 and finally, it increased to 11 percent during 2011-12. 
Jyoti Kumari Sharma

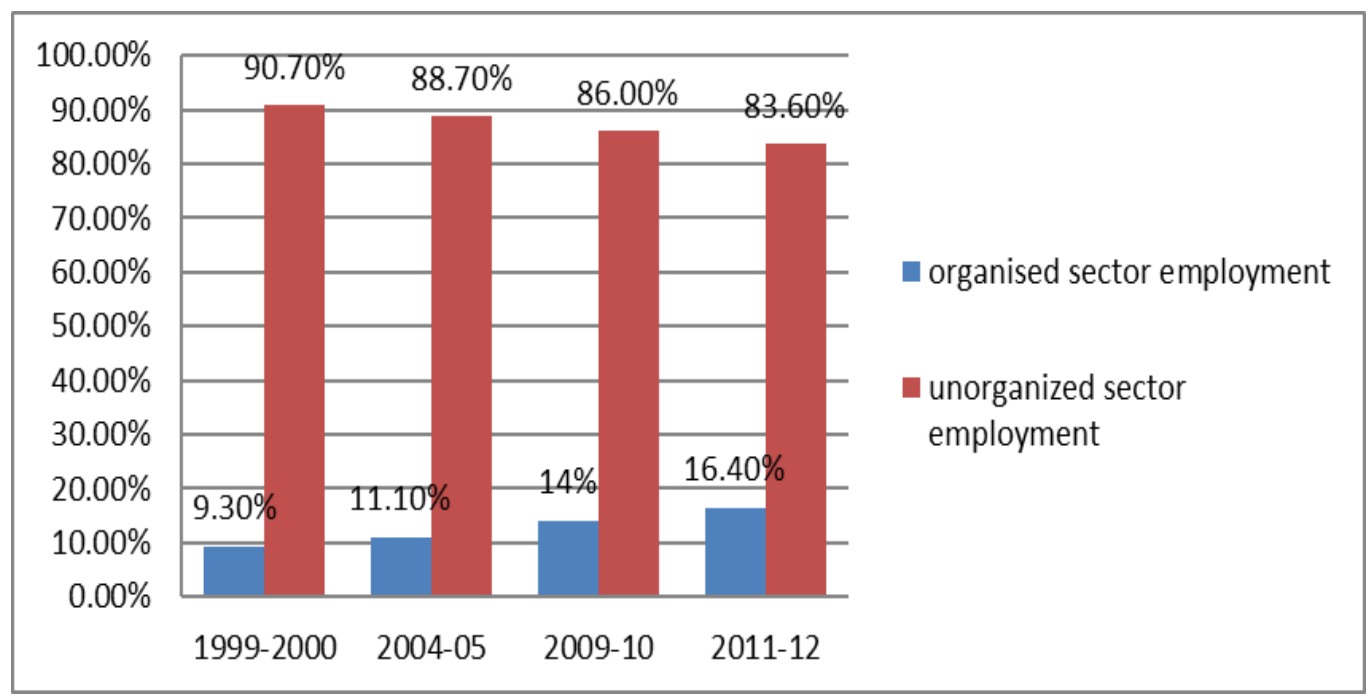

Figure 2 c): Status of employment (UPSS) related to share (\%) in total employment, with respect to organized and unorganized sector employment, from 1983 to 2011-12

It is seen from the above figure, that over the years, the percentage share of employment in the unorganized sector is always greater than the organized sector. Further, the organized sector followed an increasing trend, the unorganized sector followed by a decreasing trend. Accordingly, during 1999-2000, the organized sector employment level as compared to the unorganized sector was only 9.3 percent, which increased to 11.1 percent during 2004-05, then to 14 percent during 2009-19 and again to 16.4 percent during 2011-12. Whereas the employment of the unorganized sector was that it kept on decreasing over the years, it was 90.7 percent during 1999-2000, which decreased to 88.7 percent and 86 percent respectively during 2004-05 and 2009-10. Then it declined to 83.6 percent during 2011-12.

\subsection{HUMAN DEVELOPMENT INDEXES' OF INDIA, ALONG WITH INTERNATIONAL COMPARISON}

The Human Development Index (HDI) measures the overall achievement of a country's human resources, based on the health of its citizens, the attainment of their educational level, and their standard of living, depicting the productivity and prosperity of the concerned country. It is measured in terms of health index, education index, and income index. These indices measure the economic development of the country in terms of the development of its human capital, in the following manner. This is as follows:

Table 7: HUMAN DEVELOPMENT INDEX TRENDS IN India, as per UNDP, 2010.

\begin{tabular}{|c|c|c|c|c|c|}
\hline YEARS & $\begin{array}{c}\text { Life expectancy } \\
\text { at } \\
\text { birth }\end{array}$ & $\begin{array}{c}\text { Expected years } \\
\text { of schooling }\end{array}$ & $\begin{array}{c}\text { Mean years of } \\
\text { schooling }\end{array}$ & $\begin{array}{c}\text { GNI per capita } \\
\text { (2011 PPP\$) }\end{array}$ & HDI value \\
\hline 1990 & 57.9 & 7.6 & 3.0 & 1,882 & 0.431 \\
\hline 1995 & 60.3 & 8.2 & 3.5 & 2,188 & 0.463 \\
\hline 2000 & 62.5 & 8.3 & 4.4 & 2,683 & 0.497 \\
\hline 2005 & 64.5 & 9.7 & 4.8 & 3,387 & 0.539 \\
\hline 2010 & 66.7 & 10.8 & 5.4 & 4,403 & 0.581 \\
\hline 2015 & 68.6 & 12.0 & 6.2 & 5,674 & 0.627 \\
\hline 2016 & 68.9 & 12.3 & 6.4 & 6,075 & 0.637 \\
\hline 2017 & 69.2 & 12.3 & 6.5 & 6,446 & 0.643 \\
\hline
\end{tabular}

Source: Human Development Report, UNDP, 2019

Available on http://hdr.undp.org/sites/all/themes/hdr_theme/country-notes/IND.pdf 
With the help of the data present in the above table, we look forward to the calculation of the following indices, as per the calculation method of UNDP, 2010:

1) Health index in terms of Life expectancy of birth.

2) Education index in terms of mean years of school and expected years of schooling.

3) Income index in terms of GNI per capita income.

4) Human development index (HDI) in terms of above indices, which are health index, education index, and income index.

\subsubsection{EDUCATION INDEX}

It measures the quality of educational facilities present in the country. Earlier, as per UNDP, 1990 method of HDI calculation, the education index was measured in terms of two indicators, which are adult literacy rate and gross enrolment ratio. In 2010 it was modified by replacing these indicators by mean year of schooling and expected years of schooling, respectively. Both of these indicators were given equal weight in calculating the education index. An expected year of schooling is measured on the basis of enrolment by age at all education levels and the official age of the population at all education levels. Means year of schooling is calculated as the average number of years of education received by people age 25 and above at all education levels in their complete lifetime.

As per the new method of calculating the HDI, the UNDP report 2010, with the maximum and minimum value of all dimension indices, is shown in table- 9.2. Thus, under the maximum and minimum values of dimension indices, from the year 2010 education index is calculated in the following manner:

EDUCATION index =

EXPECTED YEARS OF SCHOOLING index + MEAN YEARS OF SCHOOLING index

2

Where; EXPECTED YEARS OF SCHOOLING index $=\frac{\text { Actual value -0 }}{18-0}$ and

MEAN YEARS OF SCHOOLING index =

Actual value -0

15- 0

Table 8: Education Index Trends In India

\begin{tabular}{|c|c|c|c|c|c|}
\hline YEARS & $\begin{array}{c}\text { Expected years } \\
\text { of schooling } \\
\text { (EYS) }\end{array}$ & $\begin{array}{c}\text { Expected years } \\
\text { of schooling } \\
\text { (EYS) INDEX* }\end{array}$ & $\begin{array}{c}\text { Mean years of } \\
\text { schooling } \\
\text { (MYS) }\end{array}$ & $\begin{array}{c}\text { Mean years of } \\
\text { schooling } \\
\text { (MYS) INDEX* }\end{array}$ & EDUCATION INDEX* \\
\hline 1990 & 7.6 & 0.422 & 3.0 & 0.2 & 0.311 \\
\hline 1995 & 8.2 & 0.455 & 3.5 & 0.233 & 0.344 \\
\hline 2000 & 8.3 & 0.461 & 4.4 & 0.293 & 0.377 \\
\hline 2005 & 9.7 & 0.538 & 4.8 & 0.32 & 0.429 \\
\hline 2010 & 10.8 & 0.6 & 5.4 & 0.36 & 0.48 \\
\hline 2015 & 12.0 & 0.666 & 6.2 & 0.413 & 0.539 \\
\hline 2016 & 12.3 & 0.683 & 6.4 & 0.426 & 0.554 \\
\hline 2017 & 12.3 & 0.683 & 6.5 & 0.433 & 0.558 \\
\hline
\end{tabular}

Source: Human Development Report, UNDP, 2019 (as in table: 9.7)

Available on http://hdr.undp.org/sites/all/themes/hdr_theme/country-notes/IND.pdf

* EXPECTED YEARS OF SCHOOLING index, MEAN YEARS OF SCHOOLING index and EDUCATION index is selfcalculated by using the above mentioned formula. 


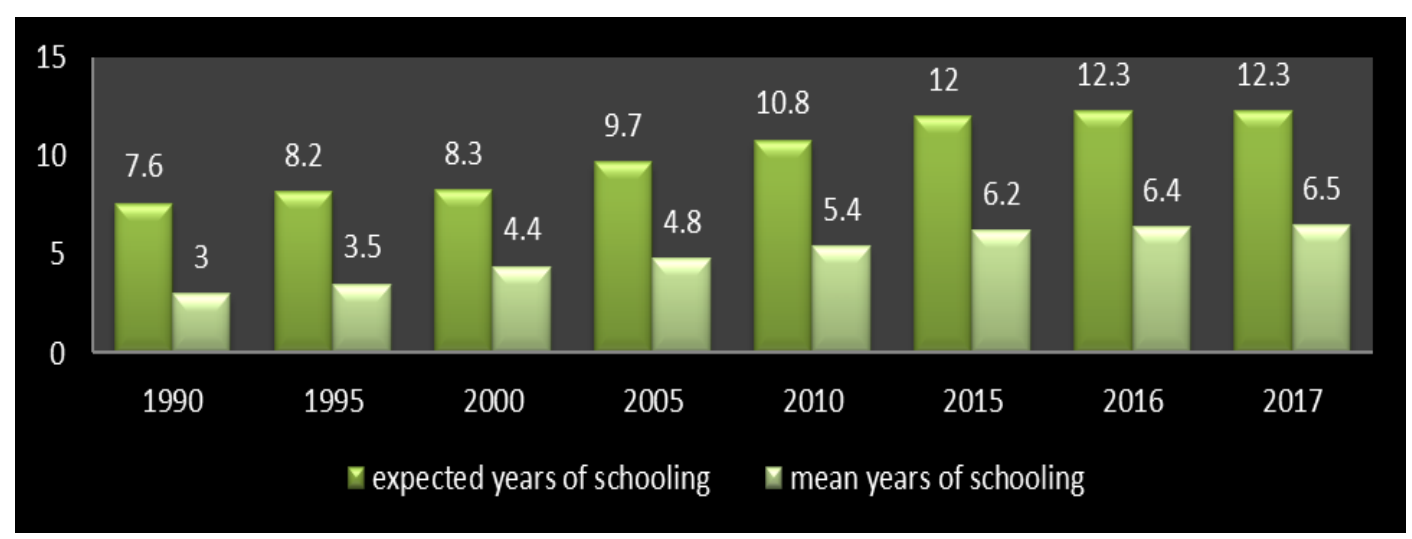

Figure 4 a): Trends of expected and means years of schooling in India

As per the above figure, we see that EXPECTED and MEAN years of schooling in India increased in the following manner, which is as follows:

- Expected years of schooling in India increased to 8.2 years in 1995 from 7.6 years in 1990 and then to 8.3 years in 2000. Accordingly, it increased to 9.7 years in the year 2005 and again to 10.8 years in 2010. In this way, in the year 2015, it increased to 12 years, and then increased to 12.3 years in 2016. Further, in 2017 it remained constant at 12.3 years.

- Mean years of schooling in India increased to 3.2 years in 1995 from 3 years in 1990 and then to 4.4 years in 2000 . Accordingly, it increased to 4.8 years in the year 2005 and again to 5.4 years in 2010. In this way, in the year 2015, it increased to 6.2 years, and then increased to 6.4 years in 2016. Further, in 2017 it increased to 6.5 years.

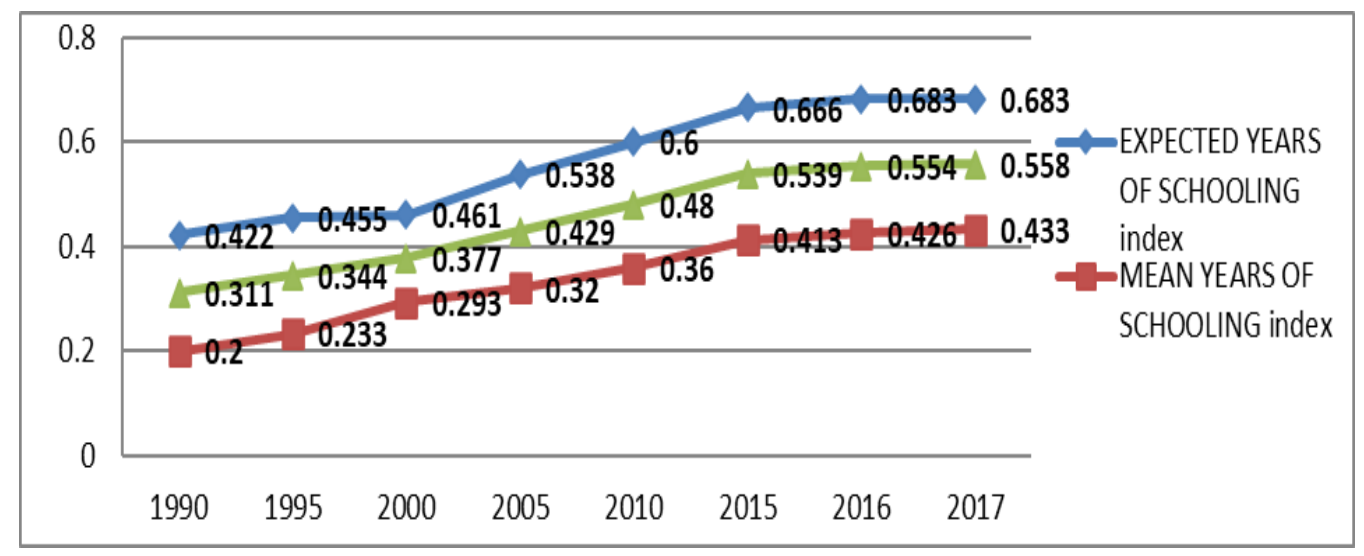

Figure 4 b): Trends of education index, in terms of expected and mean year of schooling index in India

As per the above figure, we see that EDUCATION INDEX of India increased over the years, in terms of increasing EXPECTED and MEANS YEARS OF SCHOOLING INDEX of India, in the following manner, which is as follows:

- Expected years of schooling index of India increased to 0.455 in 1995 from 0.422 in 1990 and then to 0.461 in 2000 . Accordingly, it increased to 0.538 in the year 2005 and again to 0.6 in 2010. In this way, in the year 2015, it increased to 0.666 and then increased to 0.683 in 2016 . Further, in 2017 it remained constant at 0.683 .

- Mean years of schooling index in India increased to 0.233 in 1995 from 0.2 in 1990 and then to 0.293 in 2000. Accordingly, it increased to 0.32 in the year 2005 and again to 0.36 in 2010. In this way, in the year 2015, it increased to 0.413 and then increased to 0.426 in 2016. Further, in 2017 it increased to 0.433.

Accordingly, the education index of India increased to 0.344 in 1995 from 0.311 in 1990 and then to 0.377 in 2000. Accordingly, it increased to 0.429 in the year 2005 and again to 0.48 in 2010. In this way, in the year 2015, it increased to 0.539 and then increased to 0.554 in 2016. Further, in 2017 it increased to 0.558. 


\subsubsection{HEALTH INDEX}

It measures the health facilities present in the country. As per UNDP, 1990 method of HDI calculation, the health index was calculated with respect to LIFE EXPECTANCY AT BIRTH, depicting the long and healthy life of its citizens. Under this, in 2010, the indicator of life expectancy at birth was kept the same. Here, only the minimum value of calculation was changed to 20 years.

As per the new method of calculating the HDI, the UNDP report 2010 with the maximum and minimum value of all dimension indices is shown in table 9.2. Thus, under the maximum and minimum values of dimension indices, from the year 2010 health index is calculated in the following manner:

\section{HEALTH index = LIFE EXPECTANCY AT BIRTH index =}

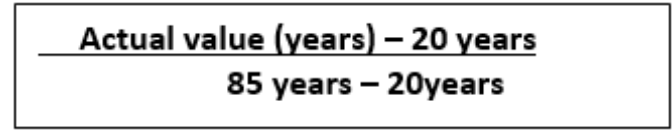

Table 9: Trends of Health Index of India

\begin{tabular}{|l|l|l|}
\hline YEARS & $\begin{array}{c}\text { Life expectancy } \\
\text { at } \\
\text { birth }\end{array}$ & $\begin{array}{l}\text { HEALTH INDEX* } \\
\text { In terms of Life } \\
\text { expectancy at birth index }\end{array}$ \\
\hline 1990 & 57.9 & 0.583 \\
\hline 1995 & 60.3 & 0.62 \\
\hline 2000 & 62.5 & 0.653 \\
\hline 2005 & 64.5 & 0.684 \\
\hline 2010 & 66.7 & 0.718 \\
\hline 2015 & 68.6 & 0.746 \\
\hline 2016 & 68.9 & 0.752 \\
\hline 2017 & 69.2 & 0.757 \\
\hline
\end{tabular}

Source: Human Development Report, UNDP, 2019 (as in table: 9.7)

Available on http://hdr.undp.org/sites/all/themes/hdr_theme/country-notes/IND.pdf

* HEALTH index is self-calculated by using the above mentioned formula.

\section{Life expectancy at birth}

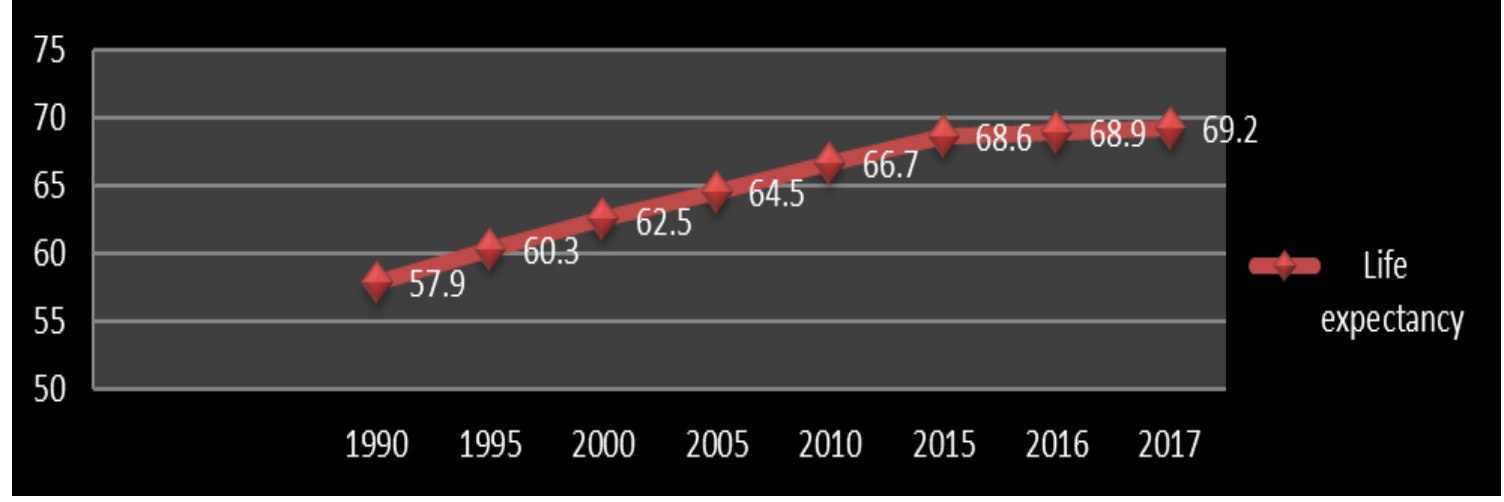

Figure 5 a): Trends of Life Expectancy at Birth (Years) In India

As per the above figure, we see that life expectancy at birth (years) in India increased to 60.3 years in 1995 from 57.9 years in 1990 and then to 62.5 years in 2000 . Accordingly, it increased to 64.5 years in the year 2005 and again to 66.7 years in 2010. In this way in the year 2015 it increased to 68.6 years, then increased to 68.9 years in 2016 and further, in 2017 it increased to 69.2 years. 


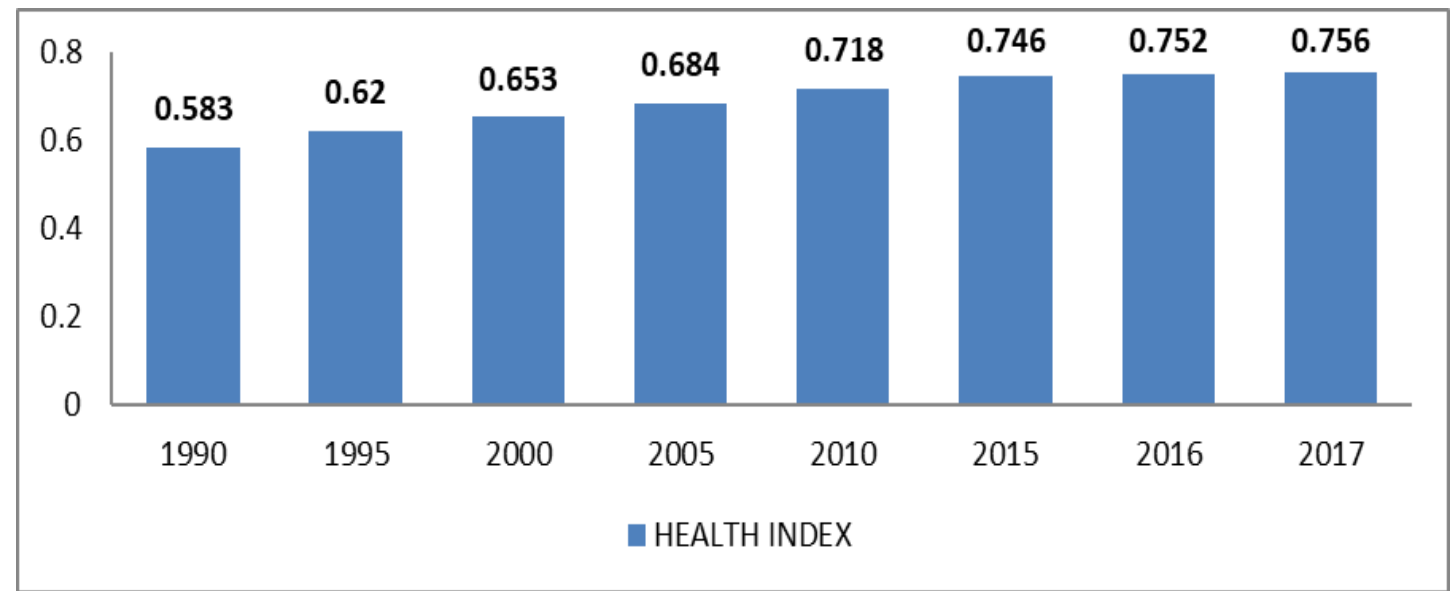

Figure 5 b): TRENDS of LIFE EXPECTANCY AT BIRTH index, that is HEALTH index in India

As per the above figure, we see that in India, the life expectancy at birth index referred to as the health index increased to 0.62 in 1995 from 0.583 in 1990 and then to 0.653 in 2000. Accordingly, it increased to 0.684 in the year 2005 and again to 0.718 in 2010 . In this way, in the year 2015, it increased to 0.746 and then increased to 0.752 in 2016 . Further, in 2017 it increased to 0.756.

\subsubsection{INCOME INDEX}

It measures the standard of living of the citizens of the country by indirectly combining it with the employment of the citizens of the country, which adds to the national income of the country. Earlier, as per UNDP, 1990 method of HDI calculation, the income index was measured in terms of GDP per capita income of the country. In 2010, it was modified, by replacing it with GNI per capita of the country. The reason for this was that it was found that in this globalized world, there is a large difference between the income of a country's residents and its domestic production, as some citizens can earn from abroad.

As per the new method of calculating the HDI, the UNDP report 2010 with the maximum and minimum value of all dimension indices is shown in table- 9.2. Thus, under the maximum and minimum values of dimension indices, from the year $2010 \mathrm{HDI}$ is calculated in the following manner:

INCOME index = GNI per capita (2011 PPP US\$) index =

$$
\frac{\log (\text { Actual value) }-\log (100)}{\log (75,000)-\log (100)}
$$

Table 10: Trends of Income Index of India

\begin{tabular}{|c|c|c|}
\hline YEARS & $\begin{array}{c}\text { GNI per capita } \\
(2011 \text { PPP\$) }\end{array}$ & $\begin{array}{c}\text { INCOME INDEX* } \\
\text { In terms of } \\
\text { GNI per capita (2011 PPP\$) index }\end{array}$ \\
\hline 1990 & 1,882 & 0.442 \\
\hline 1995 & 2,188 & 0.466 \\
\hline 2000 & 2,683 & 0.497 \\
\hline 2005 & 3,387 & 0.533 \\
\hline 2010 & 4,403 & 0.572 \\
\hline 2015 & 5,674 & 0.611 \\
\hline 2016 & 6,075 & 0.621 \\
\hline 2017 & 6,446 & 0.63 \\
\hline
\end{tabular}

Source: Human Development Report, UNDP, 2019 (as in table: 9.7)

Available on http://hdr.undp.org/sites/all/themes/hdr_theme/country-notes/IND.pdf

* INCOME index is self-calculated by using the above mentioned formula. 
Inclusive Human Resource Development - The Fruit of Inclusive Growth in India

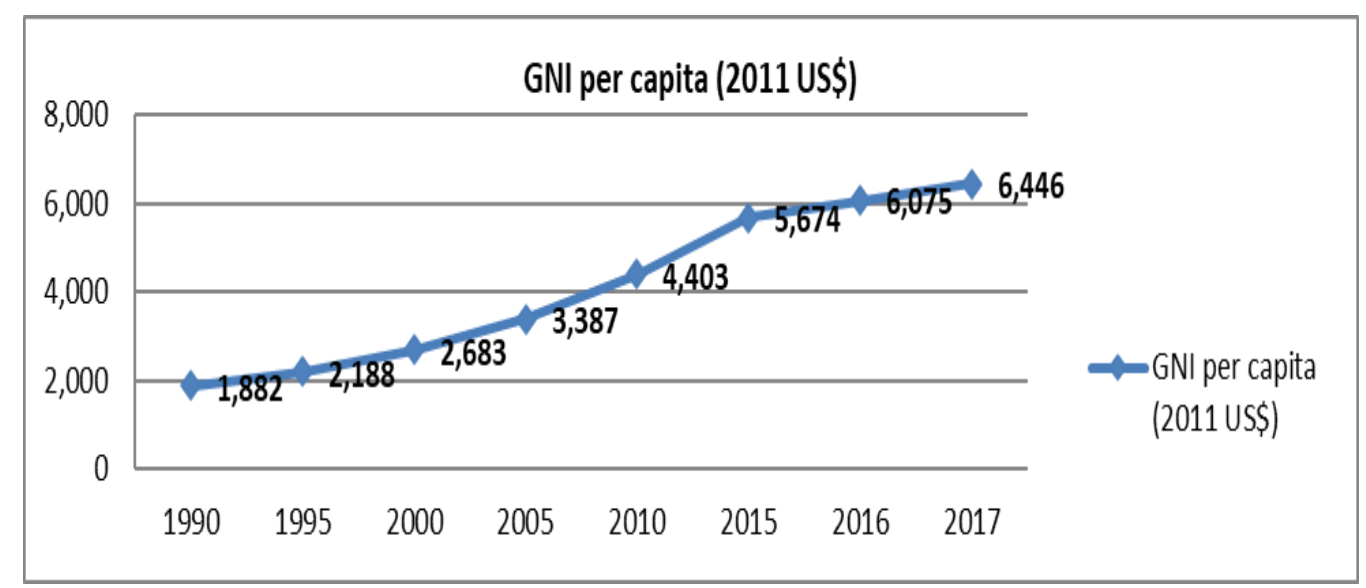

Figure 6a): Trends of GNI per capita (2011 PPP\$) in India

As per the above figure, we see that GNI per capita (2011 PPP\$) in India, increased to 2,188 ppp\$ in 1995 from 1,882 ppp\$ in 1990 and then to 2,683 ppp\$ in 2000. Accordingly, it increased to 3,387 ppp\$ in the year 2005 and again to 4,403 ppp\$ in 2010. In this way in the year 2015 it increased to 5,674 ppp\$, then increased to 6,075 ppp\$ in 2016 and further, in 2017 it increased to 6,446 ppp\$.

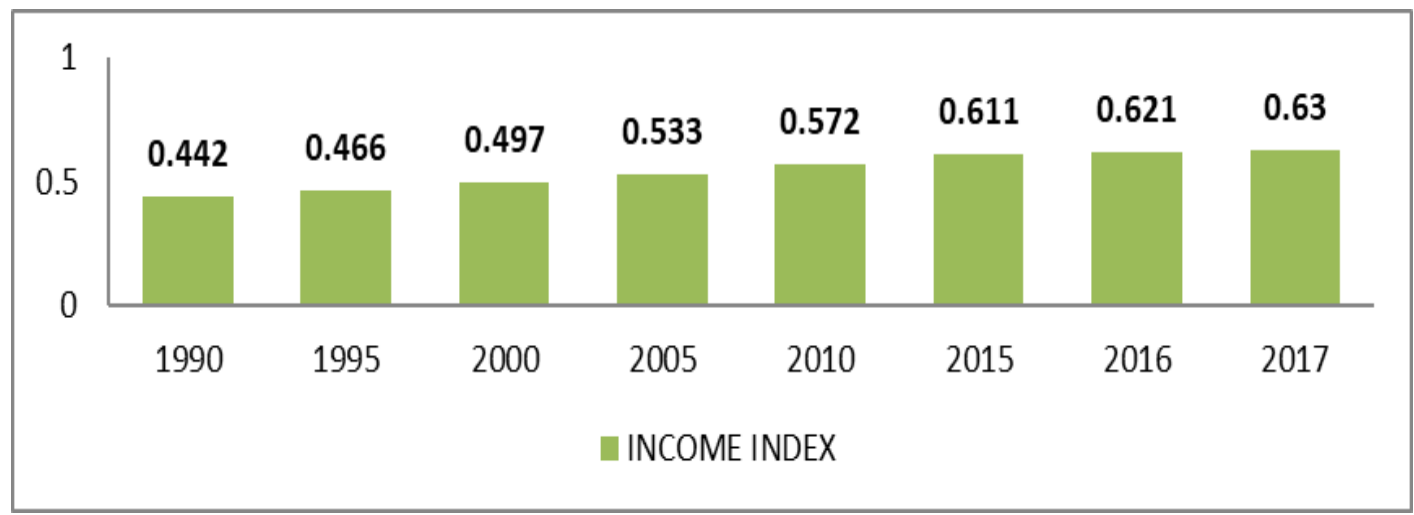

Figure 6 b): Trends of income index of India

As per the above figure, we see that in India, the income index in terms of GNI per capita (2011 PPP\$) index increased to 0.466 in 1995, from 0.442 in 1990 and then to 0.497 in 2000 . Accordingly, it increased to 0.533 in the year 2005 and again to 0.572 in 2010. In this way, in the year 2015, it increased to 0.611 and then increased to 0.621 in 2016 . Further, in 2017 it increased to 0.63.

\subsubsection{HUMAN DEVELOPMENT INDEX}

Under UNDP, the 1990 method, HDI was taken as the arithmetic mean of three-dimension indices, which is education index, the health index, and income index. During the year, 2010 the UNDP modified these indicators used to measure the progress of education and income but kept the health indicator the same. At the same time, they also modified the manner in which these indicators were aggregated for measuring HDI. That is the arithmetic mean method used for calculating HDI as per HDI the 1990 method was replaced in 2010 by the geometric mean calculation method to give equal weight to all three dimension indices.

HDI (human development index) as per UNDP, 2010 is calculated under following method:

HDI $=(\text { HEALTH index. EDUCATION index. INCOME index })^{1 / 3}$ 
Table 11: Human Development Index Trends in India

\begin{tabular}{|c|c|c|c|c|}
\hline YEARS & HEALTH INDEX $^{*}$ & EDUCATION INDEX $^{*}$ & INCOME INDEX $^{*}$ & HDI value \\
\hline 1990 & 0.583 & 0.311 & 0.442 & 0.431 \\
\hline 1995 & 0.62 & 0.344 & 0.466 & 0.463 \\
\hline 2000 & 0.653 & 0.377 & 0.497 & 0.497 \\
\hline 2005 & 0.684 & 0.429 & 0.533 & 0.539 \\
\hline 2010 & 0.718 & 0.48 & 0.572 & 0.581 \\
\hline 2015 & 0.746 & 0.539 & 0.611 & 0.627 \\
\hline 2016 & 0.752 & 0.554 & 0.621 & 0.637 \\
\hline 2017 & 0.756 & 0.558 & 0.63 & 0.643 \\
\hline
\end{tabular}

Source: Human Development Report, UNDP, 2019 (as in table: 9.7)

Available on http://hdr.undp.org/sites/all/themes/hdr_theme/country-notes/IND.pdf

It also verified by self calculation using the above mentioned formula as per UNDP, 2010 using the *values of HEALTH index, EDUCATION index and INCOME index is taken from table 8, 9 and 10.

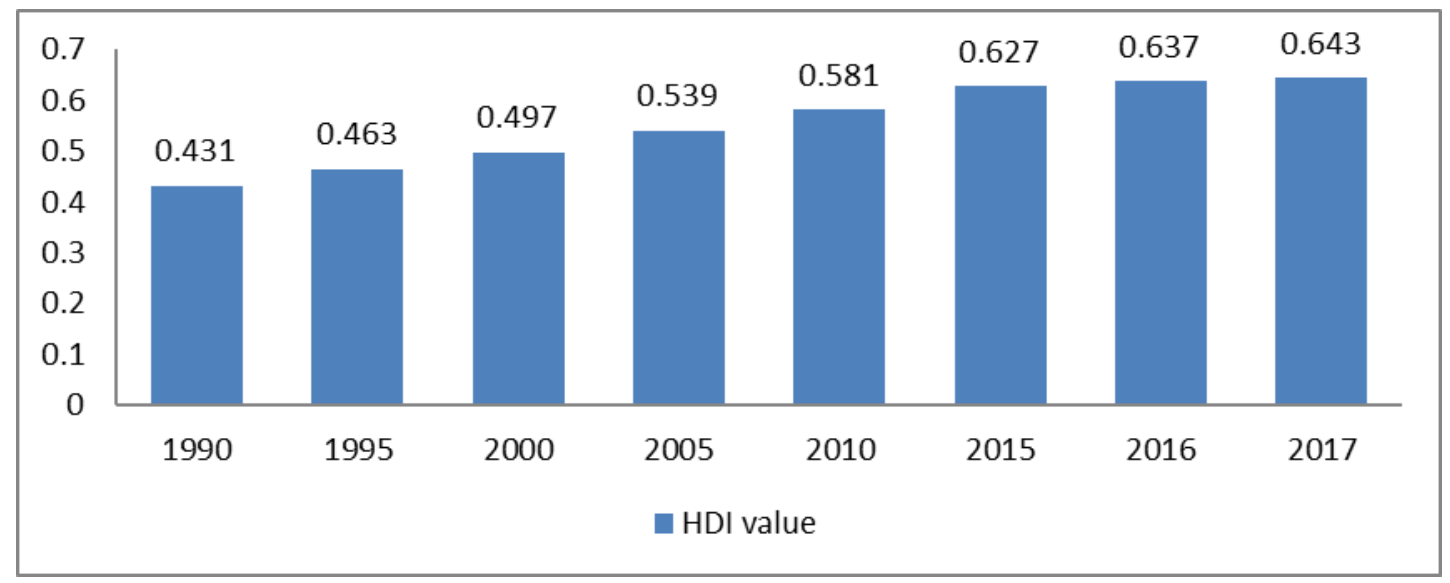

Figure 7: Human Development Index Trends in India

As per the above figure, we see that the HUMAN DEVELOPMENT INDEX (HDI) value in India, increased to 0.463 in 1995 from 0.431 in 1990 and then to 0.497 in 2000. Accordingly, it increased to 0.539 in the year 2005 and again to 0.581 in 2010 . In this way, in the year 2015, it increased to 0.627 and then increased to 0.637 in 2016 . Further, in 2017 it increased to 0.643.

Table 12: HDI from 1995-2018, Human Development Index (by UN Method) of Indian states, including the union territories since 1995

\begin{tabular}{|c|c|c|c|c|c|c|c|c|}
\hline Rank & State & HDI & HDI & HDI & HDI & HDI & HDI & Increase \\
& & 1995 & 2000 & 2005 & 2010 & 2015 & 2018 & $1995-2018$ \\
\hline 1 & KERALA & 0.562 & 0.610 & 0.694 & 0.732 & 0.770 & 0.784 & $\mathbf{\Delta} 0.222$ \\
\hline $\mathrm{UT}_{1}$ & CHANDIGARH & 0.607 & 0.642 & 0.670 & 0.658 & 0.739 & 0.774 & $\mathbf{\Delta} 0.167$ \\
\hline 2 & GOA & 0.579 & 0.623 & 0.684 & 0.751 & 0.763 & 0.764 & $\mathbf{\Delta} 0.185$ \\
\hline $\mathrm{UT}_{2}$ & LAKSHADWEEP & 0.669 & 0.711 & 0.739 & 0.729 & 0.738 & 0.749 & $\mathbf{\Delta} 0.080$ \\
\hline $\mathrm{UT}_{3}$ & DELHI & 0.630 & 0.673 & 0.700 & 0.718 & 0.734 & 0.744 & $\mathbf{\Delta} 0.114$ \\
\hline $\mathrm{UT}_{4}$ & $\begin{array}{c}\text { ANDAMAN AND NICOBAR } \\
\text { ISLANDS }\end{array}$ & 0.663 & 0.704 & 0.732 & 0.722 & 0.731 & 0.742 & $\mathbf{\Delta} 0.079$ \\
\hline $\mathrm{UT}_{5}$ & PUDUCHERRY & 0.694 & 0.738 & 0.767 & 0.756 & 0.737 & 0.739 & $\mathbf{\Delta} 0.045$ \\
\hline 3 & PUNJAB & 0.547 & 0.582 & 0.620 & 0.664 & 0.706 & 0.721 & $\mathbf{\Delta} 0.174$ \\
\hline 4 & HIMACHAL PRADESH & 0.557 & 0.596 & 0.653 & 0.675 & 0.706 & 0.720 & $\mathbf{\Delta} 0.163$ \\
\hline 5 & SIKKIM & 0.515 & 0.549 & 0.598 & 0.643 & 0.696 & 0.716 & $\mathbf{\Delta} 0.201$ \\
\hline 6 & TAMIL NADU & 0.507 & 0.546 & 0.605 & 0.655 & 0.694 & 0.708 & $\mathbf{\Delta} 0.201$ \\
\hline
\end{tabular}


Inclusive Human Resource Development - The Fruit of Inclusive Growth in India

\begin{tabular}{|c|c|c|c|c|c|c|c|c|}
\hline $\mathrm{UT}_{6}$ & DAMAN AND DIU & 0.628 & 0.669 & 0.695 & 0.686 & 0.695 & 0.706 & $\mathbf{\Delta} 0.078$ \\
\hline 7 & HARYANA & 0.515 & 0.550 & 0.594 & 0.639 & 0.687 & 0.704 & $\mathbf{\Delta} 0.189$ \\
\hline 8 & MIZORAM & 0.532 & 0.574 & 0.637 & 0.694 & 0.697 & 0.697 & $\mathbf{\Delta} 0.165$ \\
\hline 9 & MAHARASHTRA & 0.523 & 0.561 & 0.607 & 0.651 & 0.683 & 0.695 & $\mathbf{\Delta} 0.172$ \\
\hline 10 & MANIPUR & 0.525 & 0.563 & 0.603 & 0.691 & 0.699 & 0.695 & $\mathbf{\Delta} 0.170$ \\
\hline 11 & JAMMU AND KASHMIR & 0.493 & 0.530 & 0.591 & 0.646 & 0.675 & 0.684 & $\mathbf{\Delta} 0.191$ \\
\hline 12 & KARNATAKA & 0.481 & 0.517 & 0.567 & 0.610 & 0.662 & 0.682 & $\mathbf{\Delta} 0.201$ \\
\hline 13 & UTTARAKHAND & 0.594 & 0.627 & 0.655 & 0.643 & 0.662 & 0.677 & $\mathbf{\Delta} 0.083$ \\
\hline 14 & NAGALAND & 0.491 & 0.524 & 0.558 & 0.666 & 0.681 & 0.676 & $\mathbf{\Delta} 0.185$ \\
\hline 15 & GUJARAT & 0.489 & 0.526 & 0.573 & 0.608 & 0.651 & 0.667 & $\mathbf{\Delta} 0.178$ \\
\hline 16 & TELANGANA & 0.593 & 0.628 & 0.655 & 0.643 & 0.651 & 0.664 & $\mathbf{\Delta} 0.071$ \\
\hline UT 7 & DADRA AND NAGAR & 0.645 & 0.686 & 0.714 & 0.704 & 0.665 & 0.661 & $\mathbf{\Delta 0 . 0 1 6}$ \\
\hline 17 & ARUNACHAL PRADESH & 0.471 & 0.501 & 0.531 & 0.639 & 0.661 & 0.658 & $\mathbf{\Delta} 0.187$ \\
\hline 18 & TRIPURA & 0.499 & 0.532 & 0.561 & 0.613 & 0.645 & 0.655 & $\mathbf{\Delta} 0.156$ \\
\hline 19 & MEGHALAYA & 0.435 & 0.470 & 0.531 & 0.621 & 0.648 & 0.650 & $\mathbf{\Delta} 0.215$ \\
\hline 20 & ANDHRA PRADESH & 0.443 & 0.476 & 0.529 & 0.581 & 0.627 & 0.643 & $\mathbf{\Delta} 0.200$ \\
\hline 21 & WEST BENGAL & 0.474 & 0.506 & 0.540 & 0.576 & 0.620 & 0.637 & $\mathbf{\Delta} 0.163$ \\
\hline 22 & RAJASTHAN & 0.432 & 0.462 & 0.505 & 0.547 & 0.601 & 0.621 & $\mathbf{\Delta} 0.189$ \\
\hline 23 & ASSAM & 0.453 & 0.486 & 0.527 & 0.565 & 0.593 & 0.605 & $\mathbf{\Delta} 0.152$ \\
\hline 24 & CHHATTISGARH & 0.525 & 0.555 & 0.581 & 0.570 & 0.586 & 0.600 & $\mathbf{\Delta 0 . 0 7 5}$ \\
\hline 25 & ODDISHA & 0.422 & 0.452 & 0.489 & 0.533 & 0.580 & 0.597 & $\mathbf{\Delta} 0.175$ \\
\hline 26 & MADHYA PRADESH & 0.419 & 0.450 & 0.493 & 0.533 & 0.577 & 0.594 & $\mathbf{\Delta} 0.175$ \\
\hline 27 & JHARKHAND & 0.557 & 0.557 & 0.583 & 0.572 & 0.578 & 0.589 & $\mathbf{\Delta 0 . 0 3 2}$ \\
\hline 28 & UTTAR PRADESH & 0.423 & 0.454 & 0.496 & 0.529 & 0.566 & 0.583 & $\mathbf{\Delta 0 . 1 6 0}$ \\
\hline 29 & BIHAR & 0.401 & 0.430 & 0.464 & 0.511 & 0.551 & 0.566 & $\mathbf{\Delta} 0.165$ \\
\hline
\end{tabular}

Source: Available on

https://en.wikipedia.org/wiki/List_of_Indian_states_and_territories_by_Human_Development_Index

As per table 12, we see that the trends of HDI related to Indian states, including the union territories changed in the following manner between 1995 and 2018. The GREEN colour triangle denotes an increase in HDI value. It is as follows:

1) In 1995, THIRTEEN states, including all the union territories of India, were under a medium level of HDI, which is between 0.555 and 0.699 . Further, all other states were under a low level of HDI. Accordingly, in this year, among all the states of India, UTTARAKHAND was having the highest HDI value of 0.594, and BIHAR was having the lowest HDI value of 0.401. And among all the union territories of India, PUNCHERRY was having the highest HDI value of 0.694 , and CHANDIGARH was having the lowest HDI value of 0.607 .

2) In 2000, THREE of the union territories of India were having a high level of HDI that is between 0.700 and 0.799, and SIXTEEN states, including all other union territories of India, were under the medium level of HDI that is between 0.555 and 0.699. Further, all other states were under a low level of HDI. Accordingly, in this year, among all the states of India, TELANGANA was having the highest HDI value of 0.628, and BIHAR was having the lowest HDI value of 0.430 . And among all the union territories of India, PUNCHERRY was having the highest HDI value of 0.738, and CHANDIGARH was having the lowest HDI value of 0.642.

3) In 2005, FIVE union territories of India were having a high level of HDI that is between 0.700 and 0.799 , and TWENTY states, including all other union territories of India, were under the medium level of HDI that is between 0.555 and 0.699. Further, all other states were under a low level of HDI. Accordingly, in this year, among all the states of India, KERALA was having the highest HDI value of 0.694, and BIHAR was having the lowest HDI value of 0.464. And among all the union territories of India, PUNCHERRY was having the highest HDI value of 0.767, and CHANDIGARH was having the lowest HDI value of 0.670 .

4) In 2010, SEVEN were having a high level of HDI that is between 0.700 and 0.799 , of which two were states and five were the union territories of India and TWENTY FOUR states, including all other union territories of India, were under the medium level of HDI that is between 0.555 and 0.699. Further, all other International Journal of Research -GRANTHAALAYAH 
states were under a low level of HDI. Accordingly, in this year, among all the states of India, GOA was having the highest HDI value of 0.751, and BIHAR was having the lowest HDI value of 0.511 . And among all the union territories of India, PUNCHERRY was having the highest HDI value of 0.756, and CHANDIGARH was having the lowest HDI value of 0.658 .

5) In 2015, NINE were having a high level of HDI that is between 0.700 and 0.799 , of which four were states and five were the union territories of India and TWENTY-SEVEN states, including all other union territories of India, were under the medium level of HDI that is between 0.555 and 0.699 . Further, all other states were under a low level of HDI. Accordingly, in this year, among all the states of India, KERALA was having the highest HDI value of 0.770, and BIHAR was having the lowest HDI value of 0.551. Further, among all the union territories of India, CHANDIGARH was having the highest HDI value of 0.739, and DADRA AND NAGAR HAVELI was having the lowest HDI value of 0.665.

6) In 2018, THIRTEEN were having a high level of HDI that is between 0.700 and 0.799 , of which seven were states and six were the union territories of India and TWENTY THREE states, including all other union territories of India, were under the medium level of HDI that is between 0.555 and 0.699. Further, all other states were under a low level of HDI. Accordingly, in this year, among all the states of India, KERALA was having the highest HDI value of 0.770 , and BIHAR was having the lowest HDI value of 0.551 . And among all the union territories of India, CHANDIGARH was having the highest HDI value of 0.739 , and DADRA AND NAGAR HAVELI was having the lowest HDI value of 0.665 .

Table 13: HUMAN DEVELOPMENT TRENDS (1980-2018)

\begin{tabular}{|c|c|c|c|c|c|c|c|c|}
\hline COUNTRY & 1990 & 2000 & 2010 & 2013 & 2015 & 2016 & 2017 & 2018 \\
\hline NORWAY & 0.850 & 0.917 & 0.942 & 0.946 & 0.948 & 0.951 & 0.953 & 0.954 \\
\hline GERMANY & 0.801 & 0.869 & 0.920 & 0.927 & 0.933 & 0.936 & 0.938 & 0.939 \\
\hline CANADA & 0.850 & 0.868 & 0.895 & 0.910 & 0.917 & 0.920 & 0.921 & 0.922 \\
\hline UNITED KINGDOM & 0.775 & 0.867 & 0.905 & 0.914 & 0.916 & 0.918 & 0.919 & 0.920 \\
\hline UNITED STATES & 0.860 & 0.881 & 0.911 & 0.914 & 0.917 & 0.919 & 0.919 & 0.920 \\
\hline JAPAN & 0.816 & 0.855 & 0.885 & 0.900 & 0.906 & 0.910 & 0.913 & 0.915 \\
\hline FRANCE & 0.780 & 0.842 & 0.872 & 0.882 & 0.888 & 0.887 & 0.890 & 0.891 \\
\hline SRILANKA & 0.625 & 0.687 & 0.750 & 0.765 & 0.772 & 0.774 & 0.776 & 0.780 \\
\hline CHINA & 0.501 & 0.591 & 0.702 & 0.727 & 0.742 & 0.749 & 0.753 & 0.758 \\
\hline INDIA & 0.431 & 0.497 & 0.581 & 0.607 & 0.627 & 0.637 & 0.643 & 0.647 \\
\hline BHUTAN & - & - & 0.571 & 0.594 & 0.606 & 0.610 & 0.615 & 0.617 \\
\hline BANGLADESH & 0.388 & 0.470 & 0.549 & 0.572 & 0.588 & 0.599 & 0.609 & 0.612 \\
\hline NEPAL & 0.380 & 0.446 & 0.527 & 0.555 & 0.568 & 0.572 & 0.574 & 0.579 \\
\hline PAKISTAN & 0.404 & 0.449 & 0.524 & 0.537 & 0.550 & 0.556 & 0.558 & 0.560 \\
\hline
\end{tabular}

Source: Human Development Report, UNDP, 2019

Available on: http://hdr.undp.org/sites/default/files/hdro_statistical_data_table2.pdf

As per table 13, which shows HUMAN DEVELOPMENT TRENDS between 1980 and 2018, of above mentioned FOURTEEN selected countries. Here we make an international comparison of India's HDI value with developed countries and its neighbouring countries, which is as follows:

Among the above-mentioned countries every year, India always stood at 10 th rank, and the country with the highest and lowest value of HDI was as follows:

1) In 1990, UNITED STATES had the highest HDI value of 0.860 , and NEPAL was having the lowest HDI value of 0.380. In this year, INDIA was having a LOW LEVEL/DEGREE HDI VALUE of 0.431. Accordingly, among its neighbouring countries, SRILANKA and CHINA stood at a higher position-rank compared to India with the HDI value of 0.625 and 0.501, respectively. Further, countries named BANGLADESH, NEPAL, and PAKISTAN stood at a rank below India with the HDI value of $0.388,0.380$, and 0.404 , respectively.

2) In 2000, NORWAY had the highest HDI value of 0.917, and NEPAL was having the lowest HDI value of 0.446. In this year, INDIA was having a LOW LEVEL/DEGREE HDI VALUE of 0.497. Accordingly, among 
Inclusive Human Resource Development - The Fruit of Inclusive Growth in India

its neighbouring countries, SRILANKA and CHINA stood at a higher position-rank compared to India with the HDI value of 0.687 and 0.591, respectively. Further, countries named BANGLADESH, NEPAL, and PAKISTAN stood at a rank below India with the HDI value of $0.470,0.446$, and 0.449 , respectively.

3) In 2010, NORWAY had the highest HDI value of 0.942, and PAKISTAN was having the lowest HDI value of 0.524. In this year, INDIA'S HDI value increased to MEDIUM LEVEL/DEGREE HDI with HDI VALUE of 0.581. Again, as usual among its neighbouring countries, SRILANKA and CHINA stood at a higher position-rank compared to India with the HDI value of 0.750 and 0.702 , respectively. Further, countries named BHUTAN, BANGLADESH, NEPAL, and PAKISTAN stood at a rank below India with the HDI value of $0.571,0.549,0.527$, and 0.524 , respectively.

4) In 2013, NORWAY had the highest HDI value of 0.946, and PAKISTAN was having the lowest HDI value of 0.537. In this year, INDIA was also having the MEDIUM LEVEL/DEGREE HDI VALUE of 0.607. As usual among its neighbouring countries, SRILANKA and CHINA stood at a higher position-rank compared to India with the HDI value of 0.765 and 0.727 , respectively. Further, countries named BHUTAN, BANGLADESH, NEPAL, and PAKISTAN stood at a rank below India with the HDI value of $0.595,0.572,0.555$, and 0.537 , respectively.

5) In 2015, NORWAY had the highest HDI value of 0.948 , and PAKISTAN was having the lowest HDI value of 0.550. In this year, INDIA was also having the MEDIUM LEVEL/DEGREE HDI VALUE of 0.627. As usual among its neighbouring countries, SRILANKA and CHINA stood at a higher position-rank compared to India with the HDI value of 0.772 and 0.742 , respectively. Further, countries named BHUTAN, BANGLADESH, NEPAL, and PAKISTAN stood at a rank below India with the HDI value of $0.606,0.588,0.568$, and 0.550 , respectively.

6) In 2016, NORWAY had the highest HDI value of 0.951, and PAKISTAN was having the lowest HDI value of 0.556. In this year, INDIA was also having the MEDIUM LEVEL/DEGREE HDI VALUE of 0.637. As usual among its neighbouring countries, SRILANKA and CHINA stood at a higher position-rank compared to India with the HDI value of 0.774 and 0.749 , respectively. Further, countries named BHUTAN, BANGLADESH, NEPAL, and PAKISTAN stood at a rank below India with the HDI value of $0.610,0.599,0.572$, and 0.556 , respectively.

7) In 2017, NORWAY had the highest HDI value of 0.953, and PAKISTAN was having the lowest HDI value of 0.558. In this year, INDIA was also having the MEDIUM LEVEL/DEGREE HDI VALUE of 0.643. As usual among its neighbouring countries, SRILANKA and CHINA stood at a higher position-rank compared to India with the HDI value of 0.776 and 0.753 , respectively. Further, countries named BHUTAN, BANGLADESH, NEPAL, and PAKISTAN stood at a rank below India with the HDI value of $0.615,0.609,0.574$, and 0.558 , respectively.

8) In 2018, NORWAY had the highest HDI value of 0.954 , and PAKISTAN was having the lowest HDI value of 0.560. In this year, INDIA was also having the MEDIUM LEVEL/DEGREE HDI VALUE of 0.647. As usual among its neighbouring countries, SRILANKA and CHINA stood at a higher position-rank compared to India with the HDI value of 0.780 and $\mathbf{0 . 7 5 8}$, respectively. Further, countries named BHUTAN, BANGLADESH, NEPAL, and PAKISTAN stood at the rank below India with the HDI value of $0.617,0.612,0.579$, and 0.560 , respectively.

As per the statistical study made, we found that India has never crossed the high degree level of HDI till the year 2018. For this purpose, to improve the HDI status of India, we need to analyze the need for human resource development in India with reference to challenges faced by Indian government to implement HRD inclusively in India.

\section{NEED AND IMPORTANCE OF INCLUSIVE HUMAN RESOURCE DEVELOPMENT IN INDIA}

From the study made above, it is proved that human resource development in a country helps in widening the citizens' choices, heading towards the improvement in their levels of well-being, above its present-status in the country. At the same time, it should be compared to what was achieved in the past. The following factors demonstrate the need for inclusive human resource development in India, which is as follows: 
Jyoti Kumari Sharma

1) To improve the mental capability of Indian citizens through education facilities and skill development programmes.

2) To increase the productive capacity of Indian citizens under employment opportunities followed by on-thejob training programmes.

3) To improve and increase the physical capacity of Indian citizens with better health facilities.

4) To raise the standard of living of the Indian citizens with an increase in per capita income of India.

This can be done, by improving human resource productivity through an increase in literacy rate, health capacity, employment rate heading towards a reduction in the number of Indian citizens living below the poverty line.

The importance of inclusive human resource development in India arises on the basis of the fact that economic development of the country can only take place through proper and efficient utilization of its physical and natural resources by its labour force under the production process heading towards an increase in country's output. Further, under the economic terms, the country's labour force, which is the human capital of the country, is called the human resource of the country. So, to achieve inclusive growth, India needs to take steps towards inclusive human resource development. The importance of inclusive human resource development in India can be positively analyzed, as under:

1) To help Indian human capital, to efficiently utilize our country's resources under the production process, this is India's physical and natural resources. It will, in turn, increase the economic productivity of India.

2) To increase the productive capacity of our human resources heading towards an increase in the volume of output under the production process of India.

3) To increase the number of experienced Indian human resources under skill development and on-the-job training programmes, as per dynamic technological advancement taking place.

4) To get the best opportunity to use our human resources efficiently heading towards the expansion of economic development activities, along with economic welfare and the reduction of poverty in India.

5) To increase the standard of living of our human resources by a rational increase in their mental capability, productive capacity and physical capacity, heading towards the all-round development of quality of life in India.

6) To increase our per capita income concerning an increase in our national income by efficiently using all the abilities that our human resources get under the human resource development programmes.

Thus, there is a great need and importance for inclusive human resource development in India. As it will directly help the Indian citizens to develop their knowledge, health, get more employment opportunities with the improvement in their productive-physical-mental abilities. It will, in turn, motivate the Indian citizens to work hard for economic growth and development and help the Indian economy to increase their productivity.

It will finally lead to an increase in India's national income, followed by an increase in per capita income, heading towards a reduction in poverty, economic welfare with balanced regional development. Thus, it will improve the standard of living of Indians by efficient utilization of resources present in India, increasing the volume of output in every production. In this way, inclusive human resource development will lead to sustainable economic development under inclusive growth and improvement in the quality of life of Indians.

\section{CHALLENGES FACED BY INDIAN GOVERNMENT TO IMPLEMENT INCLUSIVE HUMAN RESOURCE DEVELOPMENT in INDIA}

The Indian economy has indeed gone up related to the transformation and development of human capital. But, still, it is surrounded by several weaknesses on the path of developing its human capital resources, which are citizens of India. These weaknesses act as challenges for inclusive human resource development in India, which are as follows: 


\section{1) Inadequate qualitative resources}

Despite the quantitative expansion that took place to facilitate human resource development in India still, there is a huge amount of shortfall in the qualitative factor needed for its human capital-citizens development following the principles of inclusion from all sides. For example:

- Till now, in India, there are many educational institutions, which are schools, colleges, and universities, to provide education. But still, a large number of children between ages 6-14 do not attend school in India. At the same time, the position of dropouts has also increased at a very large in recent years.

- In health facilities, we see that the number of doctors, nurses, health centers, hospitals, etc. is increasing dayby-day in India. But, still maximum doctors, nurses, etc. avoid working in rural areas of India.

- At the same time, India's public hygiene systems with respect to clean water supply, drainage, sanitary arrangements, etc. have increased in number. But, they are still qualitatively inadequate in their position and working systems related to their cleanliness and hygienic structure.

- Last but not least environmental qualitative deficiencies also exist in many areas of India with respect to dirty-lanes, marshy grounds, stinking ponds, etc.

These deficiencies mostly exist in India's rural areas or poor-unorganized areas of the urban sector of India. Thus, these facilities needed for inclusive human resource development are still grossly inadequate under qualitative terms and conditions in India.

2) Lack of full and proper adoption of advanced IT facilities

In India, still rural areas, along with the poor and unorganized area of its urban sectors, lack advancement in the fields of education, health, on-job training facilities, etc. Further, it is most unsatisfactory due to the lack of adoption of advanced modern technological facilities.

3) Existence of socio-economic imbalances

It is because of the existence of inequality related to the development of the rural and urban sectors of India. Still, in India, the human resource development system is biased against rural-human resource development, including the poor and unorganized sector sectors of urban regions. We find that in these areas, mostly Indian citizens are illiterate and unskilled. Under this, even the health facilities provided in these areas are not good. As, still Indian professionalized health resources like doctors, nurses, etc. often refuse to work in rural, traditional, poor, and unorganized areas of India. Thus, these imbalances between rural and urban areas of India act as a very big challenge to implement inclusive human resource development in India.

\section{4) Presence of Insufficient resources}

In India, the resources needed for the formation and participation of human capital are also less than what it is required for meeting the quantity and quality of education, health, job-training facilities, etc. needed for the development of the country and its human resources. The smallness of resources on public accounts creates problems in terms of allocation profiles of the different sectors, as it is often found that expenditure on education and health takes place on private account compared to public account. Besides, the resources used on the ground of social services and development, such as housing, urban development, etc. are also low. Thus, under the planning period of India, it is seen that country's resources consistently used for human resources development are often less than the resources used for the physical capital formation.

\section{5) Presence of serious inefficiencies in the human capital of India}

In India, human-capital formation faces inefficiencies. For example, in cases related to educated unemployment, many of the educated human capital resources are highly unemployed. The capabilities of the human capital of India are either not made use of (in case of open unemployment) or are underutilized (in case of underemployment). Mostly, because of this "brain-drain", the educated personnel of India moves out of the work elsewhere. Still, in many places in India, many of its citizens face illiteracy. That is why the knowledge level and skill of Indian citizens remain low. Again, since health facilities are also not good and health problems are not adequately and properly, attended by the people residing in the villages of India, the poor are in physique situations. 
Jyoti Kumari Sharma

\section{MEASURES TO BE TAKEN TO IMPLEMENT INCLUSIVE HUMAN RESOURCE DEVELOPMENT in INDIA}

The main focus and real objective of inclusive human resource development is not the growth of GDP, but to use the group of GDP, for the all-round economic development of the country, enlarging development of its citizens in terms of Human Resource Development opportunities available to them. To make inclusive human resource development a reality and advanced strategy of development, the following measures should be implemented in India. These are as follows:

1) The human balance sheet should be maintained and analyzed before starting any five-year plans in India

The human balance sheet refers to details with respect to assets and liabilities present in terms of the extent of human resources of the country. The intervention is to be made for their education, health, skill, etc. development, heading towards the reduction of the poverty level of the country in terms of the income distribution, rural-urban human capital development, rate of employment, etc. Thus, if we start our plans for inclusive human resource development in India, then the questions related to what amount of investment to be done for HRD should be answered. For this, the measures related to rural-urban HRD facilities as to where and in what amount, how can productive capacity, mental capability, etc. of citizens can be improved through HRD, should be efficiently implemented in each development plan of India, positively reducing all challenges with respect to the weakness of HRD.

2) Improving the productive capability, mental capacity, along with the physical strength of human capital

This measure is a very important development strategy of inclusive human resource development, as it can help in raising the production of the country with innovative technological advancement. Further, the highly educated, trained, and healthy human capital of the country having the good productive capability, mental capacity, and physical strength, can raise the production efficiency, along with the quality of product-output produced in the country. Thus, measures should be taken concerning the following aspects:

- Educational facilities- to improve and increase mental capacity

- Health facilities- to improve and increase physical strength.

- On-job skill development training- to improve and increase production capability and entrepreneurial ability of the respective employed citizen-human capital of the concerned country.

3) Socio-economic development plans should focus on the basic needs of human development

The target concerning the basic needs of human development refers to targets on the development of nutrition, education, health, housing, water supply, sanitation, etc. These identified targets can help in the planning under the production and consumption processes of the country. So, the Indian government should focus on the development of its citizens' basic needs requirements, as identifying the target of the national requirement and the specified nation's resources needed for development for the above mentioned basic needs under inclusion, heading towards inclusive human resource development in India.

4) For inclusive HRD, the emphasis should be given to equality of both productive and distributive measures under the human capital formation of the country

Under this, all the plans with respect to measures given above should not only see what is to be produced but, at the same time, should also take necessary actions to equally distribute it to all. It should be based on both merits and needs. For this purpose, under the development planning measure, the following processes are very important to be implemented-

- Actions should be taken to initiate programmes and mechanisms related to the production system and its delivery of services on equitable terms. It should be mostly to increase the productive capacity of poor citizens, along with wealthy and stabilized citizens, following all-inclusive terms and conditions.

- Planning should be concerned with the creation of adequate employment opportunities. Further, it should aim to provide it equally with freedom of choice, to improve stability of citizens by being employed, increasing the rate of employment of the country. Under the principles of inclusion, that is equality for all. 
5) Social and human development indicators should be evolved and monitored with every planning process to increase the plan progress in terms of human development

In this way, developing the human capital of the country with social services like housing, educational facilities, social job opportunities, etc. can reduce the poverty level of the country. Further, if the implementation and progress of human resource development programmes are monitored and evaluated under each plan, it will lead to high and progressive inclusive human resource development in the country. Accordingly, these well-monitored plans will reduce and remove the defects of previous plans, in true and stable terms and conditions with sustainability.

6) Steps should be taken to ensure full participation of all the country's human capital in inclusive growth, heading towards sustainable development

We know that that human resource development helps in the development of the other sectors of the economy, followed by effective and full human capital formation. Thus, the objective of economic planning should focus on decentralized human development strategies. Further, it should aim at full participation in human resource development, taking the benefits of it, both positively and progressively, along with the inclusive growth of complete sectors, heading towards sustainable development of the country's economy.

\section{CONCLUSION}

Human resource development is always needed for the country's development, with respect to its citizens, as per the structural environment of the country. Thus, in this way, inclusive investment in human resource development act as a process of increasing the number of citizens who can inclusively increase the productivity of the country using their education, healthy life, skill-abilities, etc. It also helps the citizens to adopt new advancement concerning technology, apprenticeship, entrepreneurial skills, etc. to improve the productivity of the institutions, companies, organizations, etc. they are employed-in. It progressively leads to an increase in the country's productivity, heading towards an increase in national income, followed by per capita income.

On this basis, it is proved that the INCLUSIVE HUMAN RESOURCE DEVELOPMENT acts as the fruit of inclusive growth that arises from activities that help increase of country's human capital productivity. It is possible only by providing education, health, and skill development facilities under employment opportunities, both inclusively and equally to all citizens heading towards human resource development of the concerned country.

\section{SOURCES OF FUNDING}

This research received no specific grant from any funding agency in the public, commercial, or not-for-profit sectors.

\section{CONFLICT OF INTEREST}

The author have declared that no competing interests exist.

\section{ACKNOWLEDGMENT}

None.

\section{REFERENCES}

[1] Desai, S.B., Dubey, A., Joshi B.L., Sen, M., Sheriff, A., and Vanneman, R. (2010): "Human Development in India: challenges for a society in Transaction"; Published by Oxford University Press, New Delhi.

Available on: https://econpapers.repec.org/RePEc:oxp:obooks:9780198065128

[2] Economic times (2018): "India 145th among 195 countries in health care access, quality". Available on https://www.economictimes.indiatimes.com 
[3] Iyengar, S. and Dholakia, R. H. (2012): "Access of the rural poor to primary health care in India." Published in journal- "Review of Market Integers", August, 2012; vol. 4, issue: 1; pp: 77-109. Available on: https://doi.org/10.1177\%2F097492921200400103

[4] Indian Pediatrics (2018): "Delivering quality health care in India: Beginning of improvement Journey"; available on https://indianpediatrics.net

[5] Jat, T.R., Ng, N., and Sebastian, M.S. (2011): "Factor affecting the use of material health services in Madhya Pradesh state of India: A multilevel analysis", published in International Journal of equity in Health, December, 2011, vol.10, issue: 1. Article number: 59, Available on: http://www.equityhealthj.com/content/10/1/59

[6] Jawahar, S.K. (2007): "Healthcare scenario in India", published in ICU Management and practice, ICU, volume 6, Issue 4, winter 2006/2007, available on: https://healthmanagement.org

[7] Krishna, R. (2017): "Seven charts that show why India's health care system needs and overhaul "; available on: https://www.livemint.com

[8] Kumar, R. (2012): "Academic institutionalization of community health services: Way ahead in medical education reforms"; published in Journal of Family Medicine and Primary Care, 2012; vol.1; issue. 1, pp: 1019.

[9] Mohanan, M., Hay, K., and Mor, N. (2016): "Quality of health care in India: challenges, priorities and the road ahead", available on https://www.healthaffairs.org

[10] Planning commission of India-12th five year plan (2012-2017): "Faster, more inclusive and sustainable growth", e social sciences-2013, available on https://econpapers.repec.org

[11] Report of steering committee of health (2012), available on https://www.planningcommission.nic.in.pdf

[12] Saha, U.G., and Saha, K.B. (2010): "A trend in women's health in India- what has achieved and what can be done", Rural remote health, April-June: 2010; vol. 10, issue: 2; 1260 . Available on https://www.pubmed.ncbi.nlm.nih.gov/20626212/

[13] Sharma, R.K., and Dhawan, S. (1986): "Health problems of rural women"; published in Popul perspect Issues1986; pp: 18-25.

[14] Singh, S. and Badaya, S. (2014): "Health care in rural India: A lack between need and feed"; published in south Asian journal of cancer, 2014, apriljune; 3(2); pp: 143-144.

[15] Yakunina, R.P., and Bychkov, G.A. (2015): “Correlation analysis of the Components of the Human Development Index across Countries", published in Procedia Economics and Finance, 24 (2015), pp: 766-771.

[16] Pradhan R.K (2016): "Planning Inclusive growth and Human Resource Development: An analysis." Available on:

https://www.researchgate.net/publication/315334416_PLANNING_INCLUSIVE_GROWTH_AND_HUMAN_D EVELOPMENT_IN_INDIA_AN_ANALYSIS

[17] Roa, T.V., Rao Raja. And Tara Yadav (2001): "A study of HRD concepts, structure of HRD departments, and HRD Practices in India, Vikalps, vol. 26, No. 1, Jan- March 2001, pp: 56-57

[18] Kumar, R.C. Human Resource Development, PP Arya and Tanden (1998). Deep and Deap Publications, pp: $37-$ 38 